\title{
Design and Implementation for the High Voltage DC-DC Converter of the Subsea Observation Network
}

\author{
Feng Zhang ${ }^{1} \mathbb{D}$, Zhifeng Zhang ${ }^{1}$, Sa Xiao ${ }^{1, * \mathbb{D}}$, Kai Xie $^{2}$, Jiawei $\mathrm{Ni}^{2}$, Haolun Gu ${ }^{2}$, Yong Wu ${ }^{1}$, Yang $\mathrm{Ning}^{1}$ \\ and Qingchao Xia ${ }^{1}$ \\ 1 State Key Laboratory of Fluid Power and Mechatronic Systems, Zhejiang University, \\ Hangzhou 310027, China; fengzh@zju.edu.cn (F.Z.); zzfwindy@zju.edu.cn (Z.Z.); 11925110@zju.edu.cn (Y.W.); \\ 3170102062@zju.edu.cn (Y.N.); mynameisxia@zju.edu.cn (Q.X.) \\ 2 Zhongtian Technology Marine Systems Co., Ltd., Nantong 226000, China; xiekai@chinaztt.com (K.X.); \\ ijiawei@chinaztt.com (J.N.); guhl@chinaztt.com (H.G.) \\ * Correspondence: sxiao@zju.edu.cn
}

Citation: Zhang, F.; Zhang, Z.; Xiao, S.; Xie, K.; Ni, J.; Gu, H.; Wu, Y.; Ning, Y.; Xia, Q. Design and Implementation for the High Voltage DC-DC Converter of the Subsea

Observation Network. J. Mar. Sci. Eng. 2021, 9, 712. https://doi.org/ $10.3390 /$ jmse9070712

Received: 17 May 2021

Accepted: 18 June 2021

Published: 27 June 2021

Publisher's Note: MDPI stays neutral with regard to jurisdictional claims in published maps and institutional affiliations.

Copyright: (c) 2021 by the authors. Licensee MDPI, Basel, Switzerland. This article is an open access article distributed under the terms and conditions of the Creative Commons Attribution (CC BY) license (https:// creativecommons.org/licenses/by/ $4.0 /)$.

\begin{abstract}
The subsea observation network has become an indispensable means of ocean exploration worldwide. However, the scale of the subsea observation network is limited by the power supply voltage and power level. Hence, to promote the development of a subsea observation network, this paper investigates the underwater high voltage DC-DC converter (HVC), which greatly improves the voltage and power level of the subsea observation network. The traditional series-parallel converter based on multi-module is faced with many technical problems, such as difficult transformer isolation, many fault points, low power density under higher input voltage level, and higher output power. The subsea HVC of this paper adopts a modular multilevel resonant DC-DC converter. The main circuit of HVC is designed in detail, including a module circuit, a resonant circuit, and a control scheme. Through the combination of the sub-module removal voltage regulation and closed-loop control, the converter can still output a stable voltage of $375 \mathrm{~V}$ when the input voltage changes. The modular sub-module and centralized transformer structure enables the converter to isolate high voltage easily, small volume, and high power density. The simulation and experiment results show the proposed HVC meets the design requirements and has good application prospects. It can be applied to submarine power transmission and distribution needs because of its wide range, large transformation ratio, and high efficiency.
\end{abstract}

Keywords: subsea observation network; electric energy conversion; modular multilevel resonant

\section{Introduction}

The subsea observation network has received increasing attention worldwide as a new and revolutionary means of ocean observation. The cabled submarine observation network has become a research hotspot in the past decade because of its powerful power supply capacity and ultra-high data transmission rate [1-4]. The basic idea is to connect the observation instruments and seabed or ocean equipment with the power grid and information network on the land through the submarine cable to extend the land observation to the depth of the ocean.

The concept of the submarine observation network originated at the end of the 20th century. The early submarine observation network projects were mainly offshore and smallscale networks, such as LEO, MVCO, HUGO, $\mathrm{H}_{2} \mathrm{O}$ [5-10]. They were simple single-node structures with low transmission voltage and power. With the continuous development of technology, the seabed observation network gradually developed into a medium- and large-scale observation network. In 2009, the U.S. Institute of MBARI established the $-10 \mathrm{kV}$ High Voltage DC power supply submarine observation network called MARS in Monterey Bay. This submarine observation network is the world's first high voltage DC power supply submarine observation network. The main cable is $57 \mathrm{~km}$ long and 
has a main node. It is deployed to the sea area with a water depth of $891 \mathrm{~m}$, and the maximum power is $9 \mathrm{~kW}$ [11]. Ocean Networks Canada (ONC, Victoria, Canada), of the University of Victoria in Canada, monitors the western and eastern coasts of Canada and the Arctic region, providing continuous real-time data for scientific research. ONC is composed of two seabed observation network systems: VENUS and NEPTUNE (Victoria, Canada). The VENUS submarine observation network has two main cables: the first one is about $4 \mathrm{~km}$ long, laid in 2006, with a depth of about $100 \mathrm{~m}$, powered by about $-400 \mathrm{~V}$ power supply, and has an independent node; the other one is about $40 \mathrm{~km}$ long, powered by $-1.2 \mathrm{kV}$ power supply, with two nodes [12]. The NEPTUNE (Canada) consists of a shore-based power supply and six nodes to form a ring network that uses a $-10 \mathrm{kV}$ power supply, with a total length of about $800 \mathrm{~km}$ of backbone cables [13]. The main part of the RSN network in the United States includes a shore-based system powered by $-10 \mathrm{kVDC}$ negative high voltage. The total length of the submarine cable is more than $850 \mathrm{~km}$, and each submarine observation node can provide a maximum power of $8 \mathrm{~kW}$ [14]. EMSO is a large-scale submarine observation network jointly constructed by 14 European countries. It includes 11 regional submarine observation networks, including several cabled submarine observation networks, such as the OBSEA submarine observation network in the Balearic Sea. However, the offshore base of its cabled submarine observation network is only about $4 \mathrm{~km}$, with small scale and low voltage and power [15]. DONET and JMA are distributed in the sea area around Japan, with the aim of realizing the long-term accurate monitoring of submarine earthquakes and tsunami. They are located in earthquake-prone areas and require a power supply and distribution system with good short-circuit resistance, and thus use a constant current power supply [16,17]. In September 2016, the primary and secondary junction boxes developed by Zhejiang University were deployed in the deep sea about $150 \mathrm{~km}$ away from the offshore base. The primary and secondary junction boxes provide a $10 \mathrm{~kW}$ power supply for ocean observation equipment and external expansion interfaces of various voltage levels $[18,19]$. Yang Fan proposed a set of fault location approach for scientific cabled seafloor observatories located in East China Sea, and the submarine observation network in this paper adopts the voltage level of $-10 \mathrm{kV}$ [20].

At present, the power supply scheme of the large-scale subsea observation networks in the world is $-10 \mathrm{kV}$ to $375 \mathrm{~V}$. It uses a switching power converter with a three-stage multi-module stacked composite structure. The secondary module consists of eight single modules, each of which uses $-210 \mathrm{~V}$ to $47 \mathrm{~V}$ double transistor forward converter, and the input and output of eight single modules are in series. Thus, a secondary module can convert $-1680 \mathrm{~V}$ to $375 \mathrm{~V}$. The highest level is a first-level module, which is composed of six second-level modules. In order to divide $-10 \mathrm{kV}$ HVDC voltage into the six second-level modules, the input sides of the six secondary modules are connected in series, and the output sides are connected in parallel, and the power conversion of $-10 \mathrm{kV}$ to $375 \mathrm{~V}$ is realized.

The traditional series-parallel converter based on multi-module has many technical problems under higher input voltage level and higher output power, such as difficult transformer isolation, many fault points, and low power density. Due to these defects, it is difficult to improve the voltage level $(-10 \mathrm{kV})$ and power level $(10 \mathrm{~kW})$, which makes the scale of the subsea observation network limited by the voltage level. Based on the abovementioned power converters in the subsea observation network, the project adopts the modular multilevel resonant DC-DC converter. The modular sub-module and centralized transformer structure enables the converter to isolate high voltage easily, is small in size, and high in power density. The voltage level is increased to $-15 \mathrm{kV}$ and the power level is increased to $40 \mathrm{~kW}$. The strategy of sub-module removal and closed-loop control cooperative voltage regulation can be applied to a wide range of large transformation ratio and high-efficiency submarine power transmission and distribution needs. 


\section{System Structure}

The subsea observatory distribution system is responsible for electric energy conversion and data transmission. A kind of observation network is illustrated in Figure 1. The tree topology in Figure 1 is widely used in the submarine observation network power distribution system. The electric power from the shore station is transmitted through a long-distance optoelectronic composite cable. The system consists of a shore station (electrical power to the junction box, commands to node experiments), branch unit (BU, branch structure of power and communication on optoelectronic composite cable), primary junction box (HVC in primary junction box for power conversion, and data communication), and science node, which consists of a secondary junction box and science instruments, for undersea science research. The work flow of the submarine observation network electrical energy conversion system is as follows: $-15 \mathrm{kV}$ high voltage electricity is converted into $375 \mathrm{~V}$ medium voltage in the primary junction box, and then $375 \mathrm{~V}$ medium voltage is input into the secondary junction box to be converted into $48 \mathrm{~V}$ low voltage required for the scientific instruments.

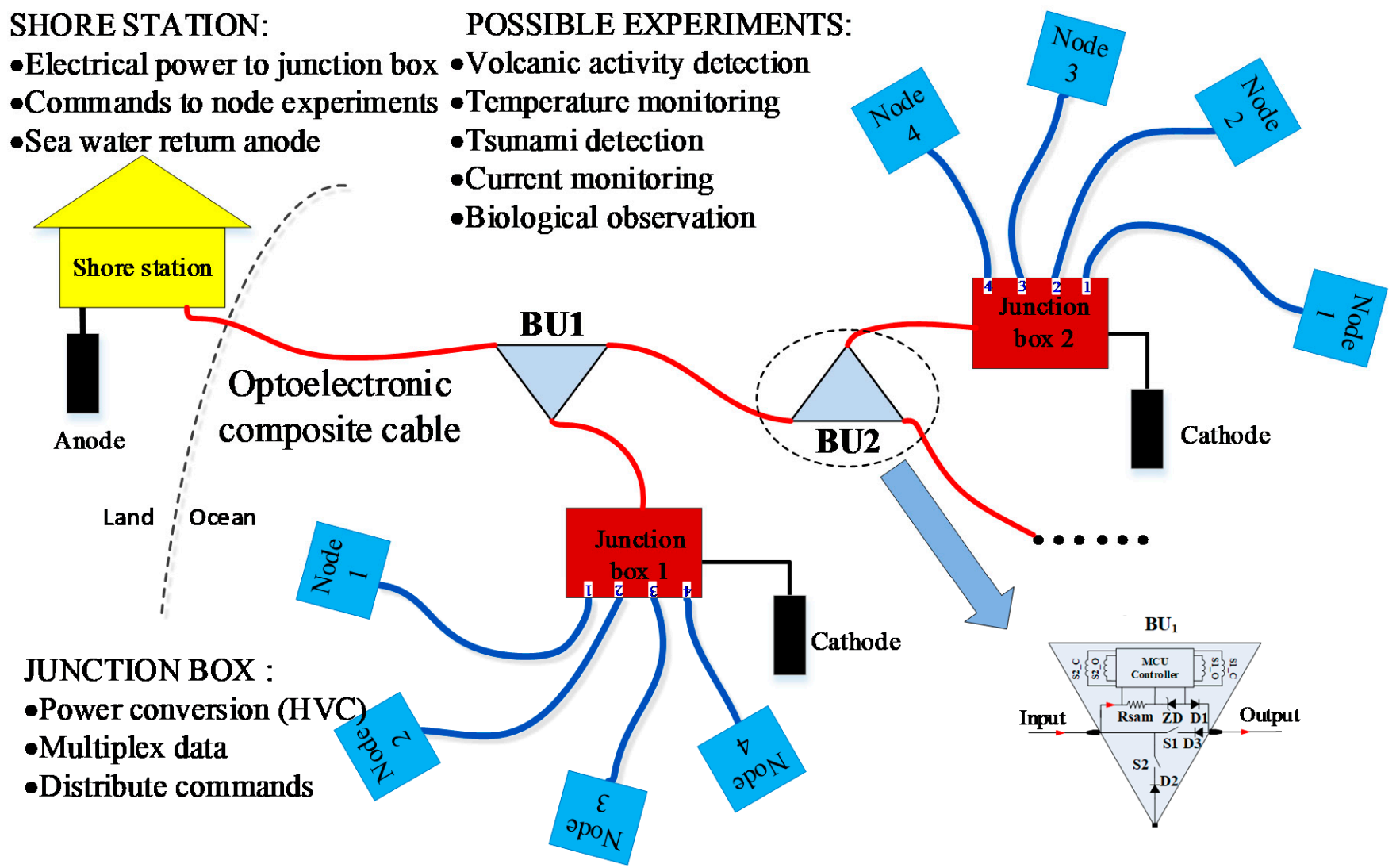

Figure 1. Structure of CV tree topology subsea observation network.

\section{Topology Design of the Main Circuit}

3.1. Topological Structure

The LLC resonant HVDC converter topology [21-23] based on the modular multilevel converter (MMC) is shown in Figure 2. The HVDC bus current can be stabilized while providing a neutral point for the resonant circuit by incorporating an HVDC capacitor into the HVDC input side to absorb the AC fluctuation of the MMC bridge arm current. The single-phase MMC structure consists of upper and lower arms, and each arm is composed of $N$ half bridge sub-modules and an arm inductor. The bridge arm inductor is connected in series with the bridge arm to suppress the bridge arm current overshoot caused by sub-module switching. Meanwhile, the two bridge arm inductors $L_{\text {leg }}$ and the leakage 
inductance $L_{\mathrm{k}}$ of the high-frequency transformer are used as the resonant inductor $L_{\mathrm{r}}$ of the LLC resonant circuit. Therefore, the resonant circuit is composed of bridge arm inductance $L_{\mathrm{leg}}$, resonant capacitor $C_{\mathrm{r}}$, leakage inductance $L_{\mathrm{K}}$ of the transformer, and excitation inductance $L_{M}$ of the high-frequency transformer. The secondary side of the transformer adopts the full-bridge uncontrolled rectifier circuit, which can better reduce the voltage and current stress of the device as compared with the full-wave rectifier. Finally, the stable DC voltage is outputted through the filter capacitor $C_{\mathrm{o}}$.

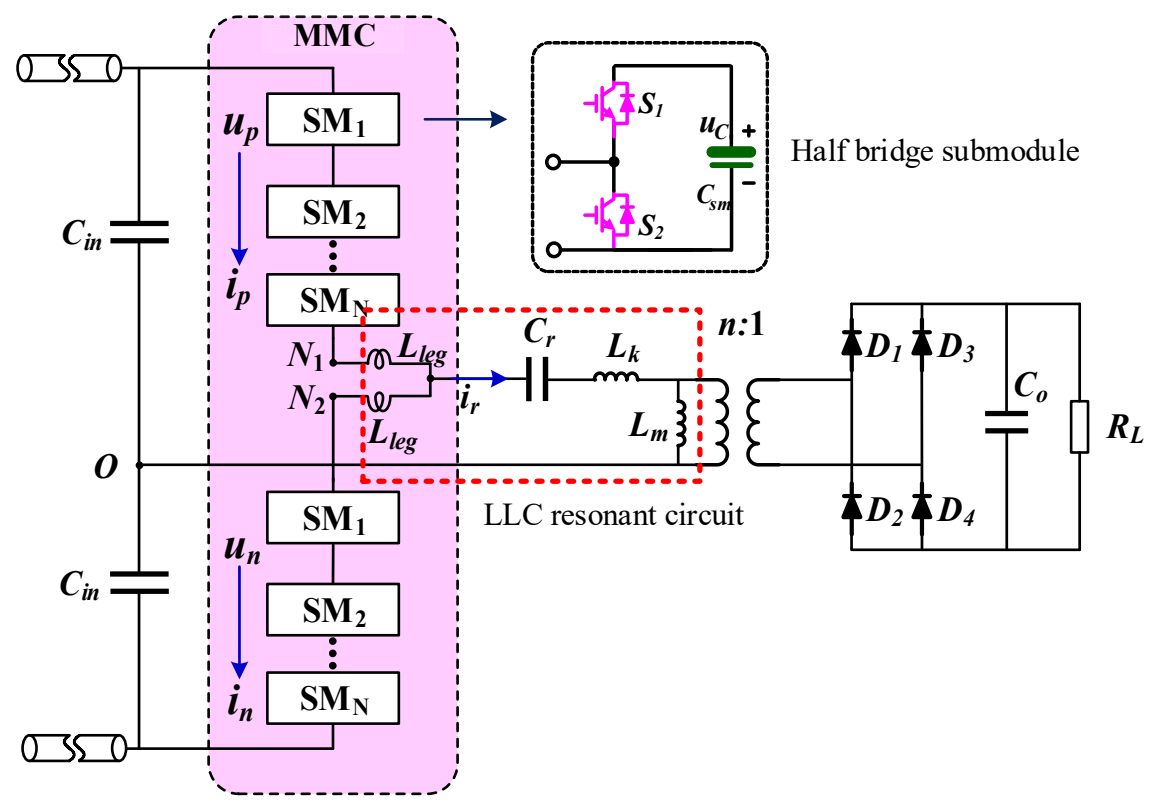

Figure 2. Resonant DC-DC converter topology based on MMC-LLC structure.

The main functions of the MMC topology in Figure 2 are as follows. The DC voltage is converted into a high-frequency square wave and applied to the input of the resonant circuit. In this paper, the ladder wave modulation method of the approximate square wave is adopted, as shown in Figure 3. The characteristics of the output square wave of the half-bridge structure are simulated to improve the utilization rate of DC voltage. The ladder wave output can also avoid high DC input voltage applied directly to the primary side of the transformer, reduce the $d v / d t$ primary side of the transformer, facilitate the design of the transformer, and reduce the issues in manufacturing. When the input voltage or load changes, the feed-forward control link adjusts the output voltage by adjusting the number of upper and lower bridge arm switching sub modules.

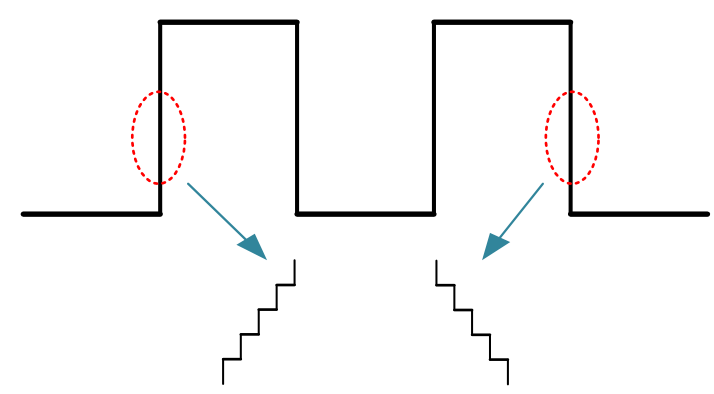

Figure 3. Bridge arm voltage modulation mode. 
The LLC resonant circuit in Figure 2 has two resonant points: resonant frequency $f_{\mathrm{r}}$ composed of $L_{\mathrm{r}}$ and $C_{\mathrm{r}}$, and resonant frequency $f_{\mathrm{m}}$ composed of $L_{\mathrm{r}}+L_{\mathrm{m}}$ and $C_{\mathrm{r}}$. That is,

$$
f_{\mathrm{r}}=\frac{1}{2 \pi \sqrt{L_{\mathrm{r}} C_{\mathrm{r}}}}, f_{\mathrm{m}}=\frac{1}{2 \pi \sqrt{\left(L_{\mathrm{r}}+L_{\mathrm{m}}\right) C_{\mathrm{r}}}}
$$

when the input square wave frequency $f_{\mathrm{S}}$ of the resonant circuit is equal to $f_{\mathrm{r}}$, the gain of the resonant circuit is 1 ; when the input square wave frequency $f_{\mathrm{s}}$ of the resonant circuit is greater than $f_{\mathrm{r}}$, the gain of the resonant circuit is less than 1 . Meanwhile, when the input square wave frequency $f_{\mathrm{s}}$ of the resonant circuit is less than $f_{\mathrm{r}}$, the gain of the resonant circuit will be greater than 1 . The detailed working principle and parameter design of the topology are given in the following sections.

\subsection{Voltage Regulation Scheme of Sub-Module Removal}

Its voltage regulation mode has multiple control degrees of freedom based on the MMC-LLC HVDC converter topology. The voltage regulation scheme adopted in this paper is the combination of sub-module removal voltage regulation and closed-loop frequency conversion voltage regulation. The sub-module removal voltage regulation is used as feedforward control, and the voltage regulation is used mainly to deal with the wide ranging change in input voltage. The corresponding working waveform is shown in Figure 4 . The voltage regulation method uses the concept of $\mathrm{MMC}$ voltage modulation ratio to change the AC output side of $M M C$, that is, the square wave size of the resonator input to adjust the final output DC voltage. When the input voltage of the converter is from $-9 \mathrm{kV}$ to $-15 \mathrm{kV}$, it needs to output $375 \mathrm{~V} \mathrm{DC}$ voltage stably. Therefore, the purpose of the sub-module removal voltage regulation scheme is to ensure that the square wave applied to the input of the resonant circuit can be stabilized by adjusting the number of sub-modules on the upper and lower arms of MMC under different input voltages.
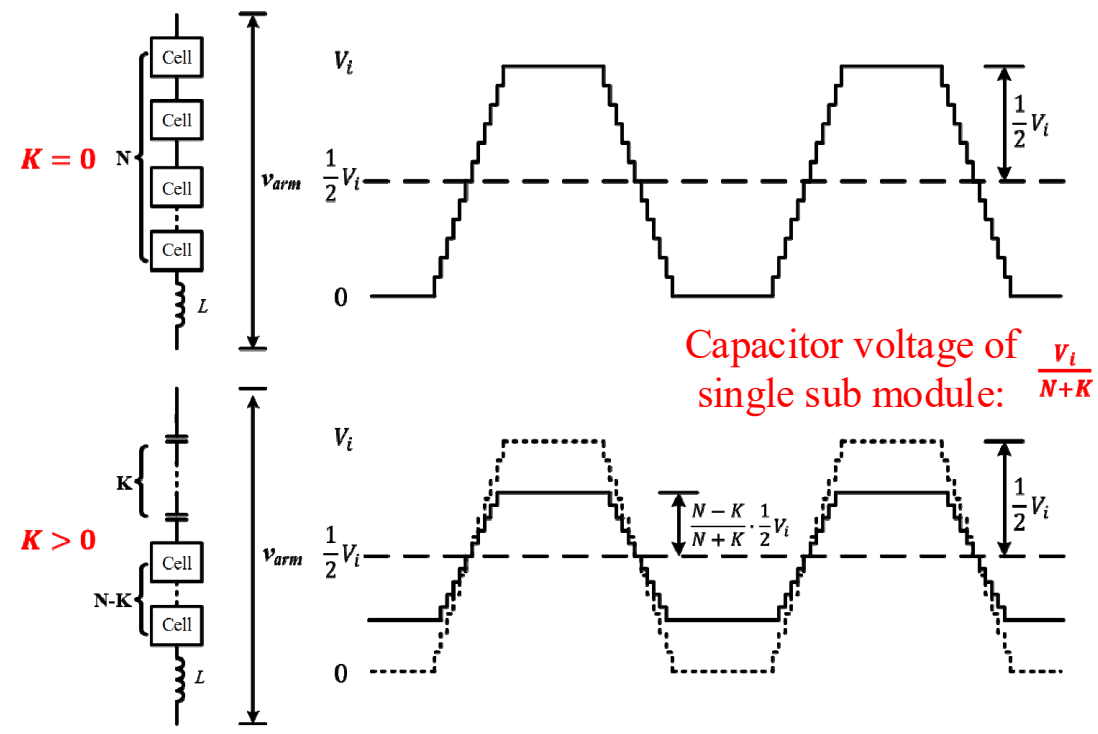

Figure 4. Voltage waveform of bridge arm under sub-module removal voltage regulation.

The working principle of sub-module voltage regulation is to change the voltage range of the MMC bridge arm by selecting whether the capacitor of $K$ sub-modules in the upper and lower bridge arms of MMC remains when placed into the circuit to realize voltage regulation. When $K=0$, as shown in the upper part of Figure 4, all the sub-modules in the MMC bridge arm are normally on and off. All the sub-modules in each bridge arm are also either on or off except for the edge switching process. At this time, the output voltage range of the MMC single bridge arm is $0-V_{\mathrm{i}}\left(V_{\mathrm{i}}\right.$ is the input voltage $\left.V_{\mathrm{dc}}\right)$, and the output voltage amplitude of the modular inverter is $V_{\mathrm{i}} / 2$. When $K>0$, as shown in the lower 
part of Figure 4, the $K$ sub-module capacitances in the MMC bridge arm are connected to the bridge arm in series all the time, and the number of sub-modules inserted into the circuit at most is $N+K$, and the capacitance-voltage of sub-module is $V_{\mathrm{i}} /(N+K)$. A bias between $v_{\text {arm } 1}$ and $v_{\text {arm2 }}$ can be found and is $K V_{\mathrm{i}} /(N+K)$. The peak-to-peak amplitude of the AC component is $(N-K) V_{\mathrm{i}} /(N+K)$. At this time, the output voltage amplitude of the modular inverter circuit becomes

$$
(N-K) /(N+K) \times V_{\mathrm{i}} / 2 .
$$

In this paper, the input voltage is required to vary from $-9 \mathrm{kV}$ to $-15 \mathrm{kV}$, and thus, when the input voltage is $-9 \mathrm{kV}$, all the MMC bridge arm sub-modules are put into operation or cut off, that is, when $K=0$, the square wave voltage applied to the input of the resonant circuit is $\pm 4.5 \mathrm{kV}$. With the increase of input voltage, to keep the square wave at the AC output end of MMC, that is, the square wave applied at the input end of resonant circuit unchanged, $K$ needs to be increased. Since $K$ must be an integer, there is a certain error, which needs to be adjusted by further closed-loop control.

\subsection{Closed-Loop Control}

Due to the step fluctuation of the output voltage, it is necessary to adjust the frequency of the output voltage by closed-loop control to reduce the error of the output voltage. The block diagram of the closed-loop control system is shown in Figure 5. The feedforward part determines the number of sub-modules $K$ inserted into the bridge arm by sampling the input voltage, and the feedback part determines the square wave frequency $f_{\mathrm{s}}$ of the resonant circuit by sampling the output voltage and the compensation network. The central controller sorts the capacitor voltage of the bridge arm sub-modules to determine which sub-modules are switched on and off and then generates the control signal.

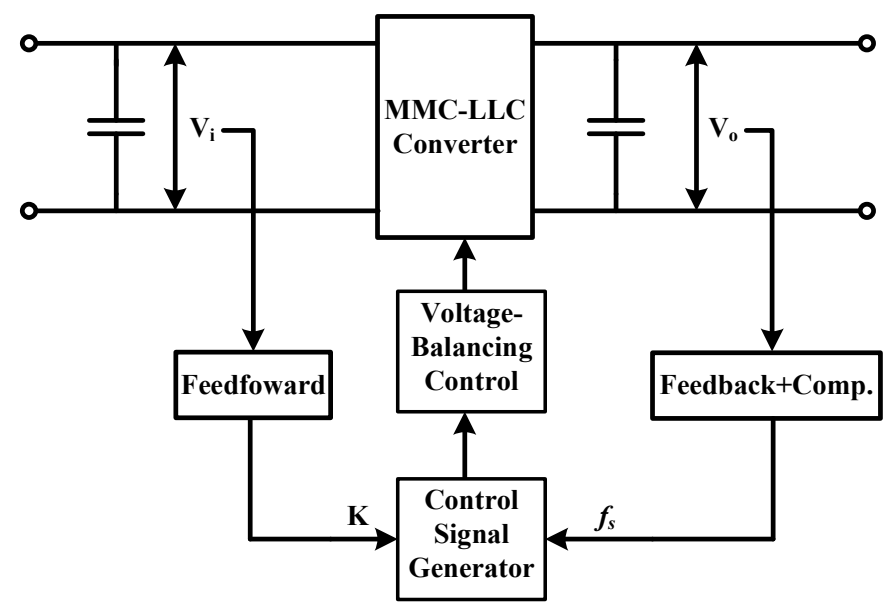

Figure 5. Block diagram of closed-loop control system.

The control system structure of the system is shown in Figure 6. The main controller adopts the combination of DSP and FPGA. The main functions of DSP include closed-loop voltage stabilizing control, soft start of the main circuit, state monitoring and protection of the converter, communication with the upper computer, etc. FPGA is the interaction center between the main controller and the sub-controller, which is responsible for multiple tasks such as module voltage sharing control, drive signal modulation, communication coding, and decoding. 


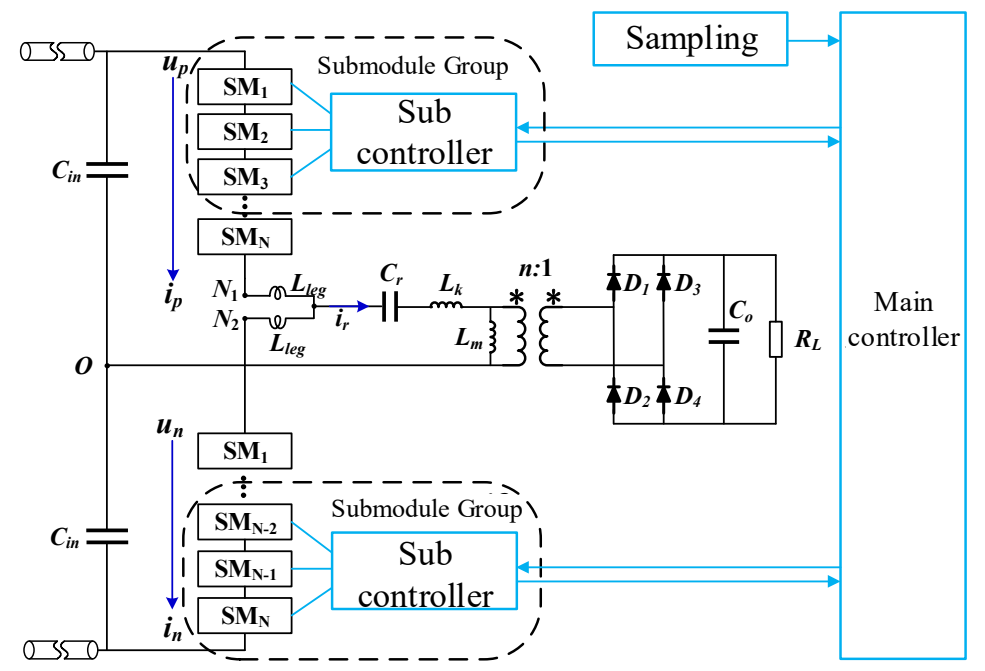

Figure 6. Structure of control system.

Each sub-controller controls three sub-modules, called a sub-module group, as shown in Figure 7. The sub-controller converts the received control signals into the real-time driving and protection signals of each sub-module, sends them to the sub-module for control and sends the voltage and operation status data of the sub-module to the main controller.

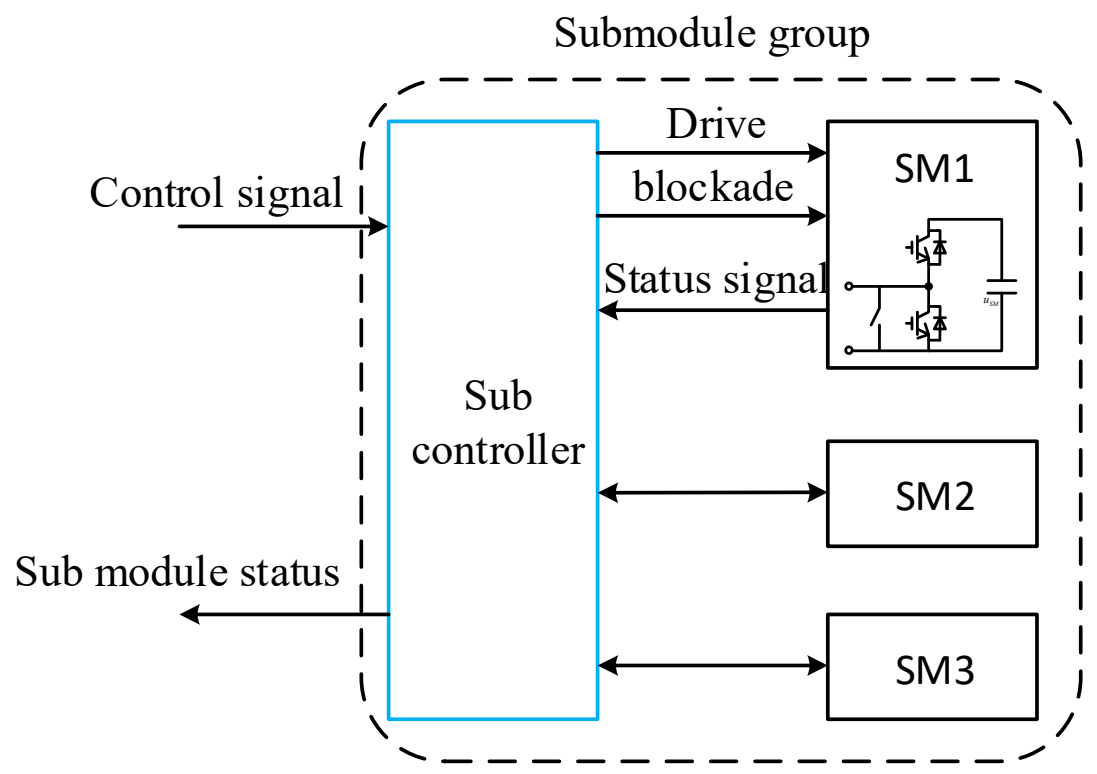

Figure 7. Structure of sub-module group.

\subsection{Error of Sub-Module Voltage Regulation}

To maintain the output voltage stability of the converter under different HVDC input voltages, the output voltage of MMC at the input port of the resonant network should be $\pm 4.5 \mathrm{kV}$ as far as possible. When the input voltage is $-9 \mathrm{kV}$, the output voltage range of the MMC bridge arm should be $-9 \mathrm{kV} \sim 0$ when the input voltage is $-12 \mathrm{kV}$, the output voltage range of the MMC bridge arm should be $-10.5 \mathrm{kV} \sim-1.5 \mathrm{kV}$ when the input voltage is $-15 \mathrm{kV}$, the output voltage range of MMC bridge arm should be $-12 \mathrm{kV} \sim$ $-3 \mathrm{kV}$, that is when the DC input voltage is $V_{\mathrm{in}}$, the output voltage range of bridge arm should be $\left(V_{\text {in }} / 2-4.5 \mathrm{kV}, V_{\text {in }} / 2+4.5 \mathrm{kV}\right)$. Therefore, the maximum output voltage of the MMC bridge arm is required to be less than the DC input voltage. Considering the characteristics of power devices of various voltage levels, the scheme adopts a 1200V IGBT 
single transistor, and the maximum working voltage of the sub-module is $800 \mathrm{~V}$. Therefore, the number of sub-modules required for a single bridge arm is as follows:

$$
N=\frac{12 \mathrm{kV}}{800 \mathrm{~V}}=15
$$

Considering that each bridge arm has three redundant sub-modules, the total number of sub-modules required for the upper and lower bridge arms is 36 .

According to Equations (2) and (3), the error of sub-module voltage regulation can be obtained when $K$ takes different values shown in Figure 8.

The curve of the shadow part in Figure 8 shows the error of sub-modules removal voltage regulation under different input voltage. It can be concluded that since $\mathrm{K}$ can only be taken as an integer, the error of sub-module voltage regulation is about $\pm 7 \%$.

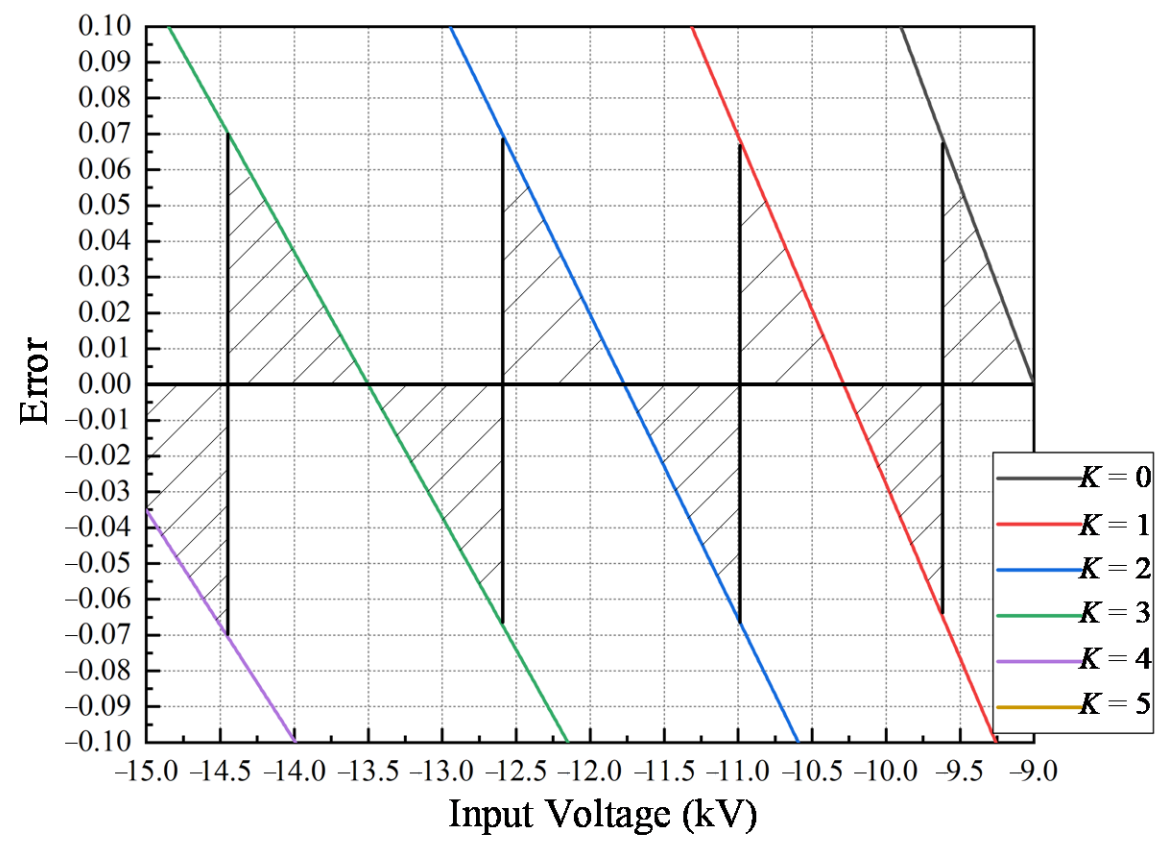

Figure 8. Error of sub-module voltage regulation with a different $K$ value.

\section{Topological Parameters of the Main Circuit}

\subsection{Resonant Unit}

According to the voltage regulation scheme described in the previous section, no matter how much the normal HVDC input voltage and load are, the MMC bridge arm will adjust the number of switching sub-modules, and the output amplitude is approximately $\pm 4.5 \mathrm{kV}$ square waves as far as possible, which is applied to the input end of the resonant circuit. Therefore, the ratio of primary and secondary side turns of the transformer should be designed as follows:

$$
n=\frac{4.5 \mathrm{kV}}{375 \mathrm{~V}}=12
$$

Since using only the sub-module to switch the voltage regulation is a step-by-step regulation, some errors will occur, and Figure 8 shows that the error is $\pm 7 \%$. Therefore, this scheme further makes the output voltage maintained at DC $375 \mathrm{~V}$ by closed-loop frequency modulation control. The parameters of the resonant network should be designed to make the gain of the resonant network adjustable between 0.93 and 1.07 in the adjustable frequency range. 
Figure 9 is the equivalent circuit of the resonant circuit obtained by the first harmonic approximation (FHA). In the figure, the MMC bridge arm inductance and the transformer leakage inductance together form the resonant inductance $L_{r}$, that is,

$$
L_{\mathrm{r}}=L_{\mathrm{leg}} / 2+L_{\mathrm{k}}
$$

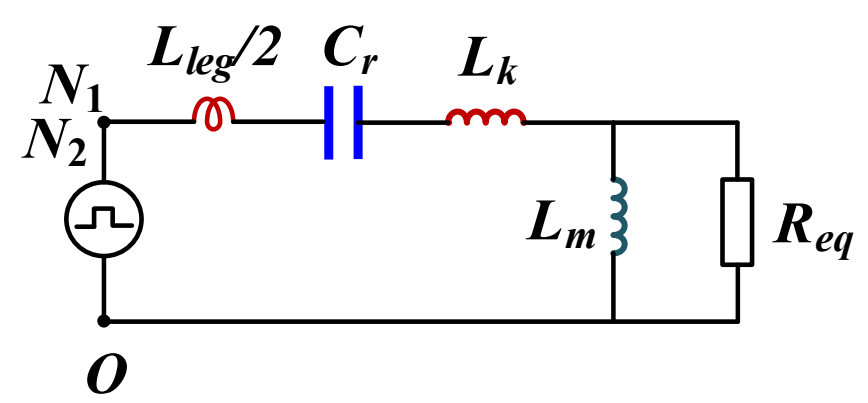

Figure 9. Approximate equivalent circuit of the resonant unit fundamental wave.

$R_{\text {eq }}$ is the equivalent resistance of the load converted to the primary side of the transformer, which is determined by the following formula:

$$
R_{\mathrm{eq}}=\frac{8}{\pi^{2}} n^{2} R_{o}=\frac{8}{\pi^{2}} n^{2} \frac{V_{o}^{2}}{P_{o}}
$$

According to Equation (6), the equivalent resistance $R_{\mathrm{eq}}$ is found to be related to the load (i.e., output power), and thus, the gain of the resonant network will change under different loads.

The switching loss limit of IGBT in the MMC bridge arm sub-module and the volume of a high-frequency transformer are limited by frequency limitation. Thus, after estimation, the resonant frequency is set as $10 \mathrm{kHz}$ in this scheme. Under normal closed-loop frequency and voltage regulation, the maximum switching frequency is set as $12 \mathrm{kHz}$ and the minimum switching frequency is set as $8 \mathrm{kHz}$. Therefore, the resonant inductor $L_{\mathrm{r}}$ and resonant capacitor $C_{\mathrm{r}}$ satisfy the following relations:

$$
f_{\mathrm{r}}=\frac{1}{2 \pi \sqrt{L_{\mathrm{r}} C_{\mathrm{r}}}}=10 \mathrm{kHz}
$$

According to the concept of quality factor $Q$ and inductance ratio $\lambda$ in the resonant circuit, they are defined as follows:

$$
\begin{gathered}
Q=\frac{\omega_{\mathrm{r}} L_{\mathrm{r}}}{R_{\mathrm{eq}}}=\frac{2 \pi f_{\mathrm{r}} L_{\mathrm{r}}}{R_{\mathrm{eq}}} \\
\lambda=\frac{L_{\mathrm{r}}}{L_{\mathrm{m}}}
\end{gathered}
$$

Equations (7)-(9) show that the relationship among resonant inductor $L_{r}$, resonant capacitor $C_{\mathrm{r}}$, and excitation inductor $L_{\mathrm{m}}$ is restricted by resonant frequency $f_{\mathrm{r}}$, quality factor $Q$, and inductance ratio $\lambda$. Combined with the classic LLC gain derivation method, taking normalized square wave frequency $f_{\mathrm{n}}=f_{s} / f_{r}$, quality factor $Q$, and inductance ratio $\lambda$ as independent variables, the relationship between resonant network DC gain $M$ and the three independent variables can be expressed as follows:

$$
M\left(f_{\mathrm{n}}, Q, \lambda\right)=\frac{1}{\sqrt{\left(1+\lambda-\frac{\lambda}{f_{\mathrm{n}}^{2}}\right)+Q^{2}\left(f_{\mathrm{n}}^{2}-\frac{1}{f_{\mathrm{n}}^{2}}\right)}}
$$


Figure 10 shows the relationship between DC gain and frequency by changing the quality factor $Q$ under the premise of constant inductance ratio $\lambda$. The results show that (1) when the square wave frequency $f_{\mathrm{s}}$ is equal to the resonant frequency $f_{\mathrm{r}}$, regardless of the $Q$ value, the DC gain of the resonant network is 1 , that is, other circuit conditions are certain, regardless of how much the output load is, the rated DC voltage can be stably outputted at the resonant point, and the working efficiency of the circuit is also the highest. (2) With the decrease of $Q$, the DC gain of the resonant circuit at low frequency (square wave frequency is slightly less than resonant frequency) increases, that is, the smaller $Q$, the stronger amplification ability of the resonant circuit at low frequency. In the high-frequency part (the square wave frequency is greater than the resonant frequency), the sensitivity of gain to frequency decreases with the decrease of $Q$. A higher switching frequency is needed to achieve a larger range of gain. Therefore, selecting an appropriate $Q$ value to synthesize the gain characteristics of low and high frequencies is necessary.

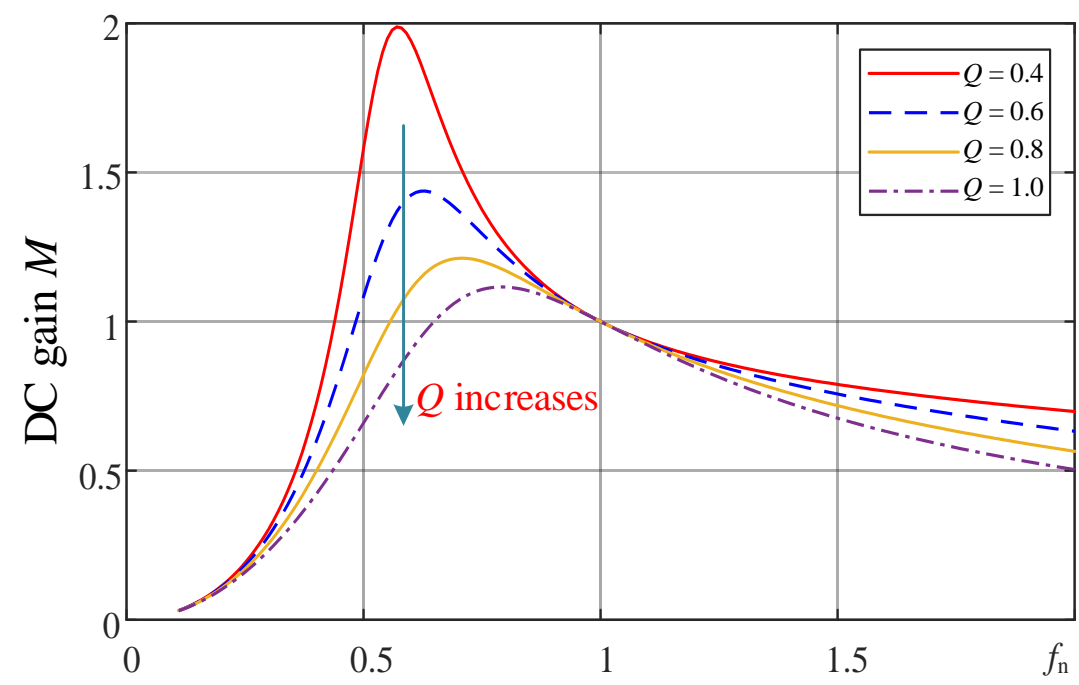

Figure 10. Effect of quality factor $Q$ on DC gain $(\lambda=0.4)$.

Figure 11 shows the effect of inductance ratio $\lambda$ on DC gain under the premise of certain quality factor $Q$. The results show that (1) when the square wave frequency $f_{\mathrm{s}}$ is equal to the resonant frequency $f_{\mathrm{r}}$, the DC gain is 1 regardless of the inductance ratio and (2) with the increase of $\lambda$, DC gain is more sensitive to the frequency in both high and low-frequency regions. When the input DC voltage changes, the frequency modulation is more sensitive, and the frequency variation range will not be very wide. However, on the premise that the excitation inductance $L_{\mathrm{r}}$ is constant, the larger $\lambda$ means the excitation inductance $L_{\mathrm{m}}$ will be smaller, which will inevitably lead to a larger excitation current and greater loss. Therefore, for the selection of $\lambda$, it is necessary to consider comprehensively the gain characteristics and excitation current. 


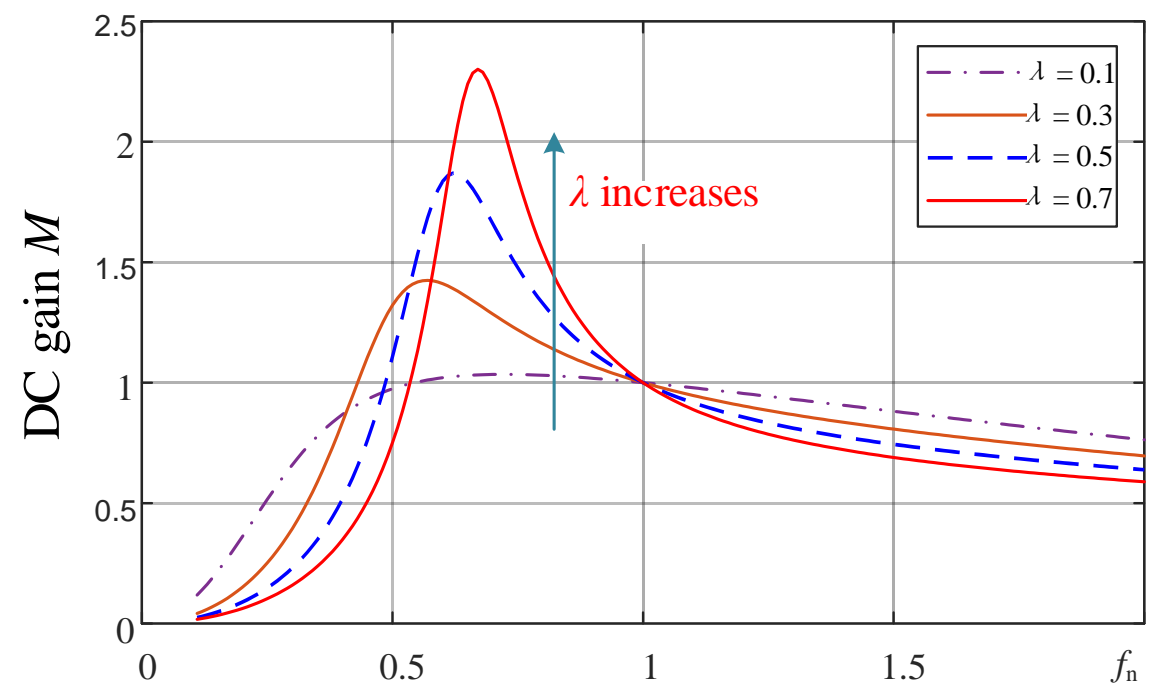

Figure 11. Effect of inductance ratio $\lambda$ on $D C$ gain $(Q=0.5)$.

We can summarize the design process of resonant network parameters according to the above design ideas as shown in Figure 12.

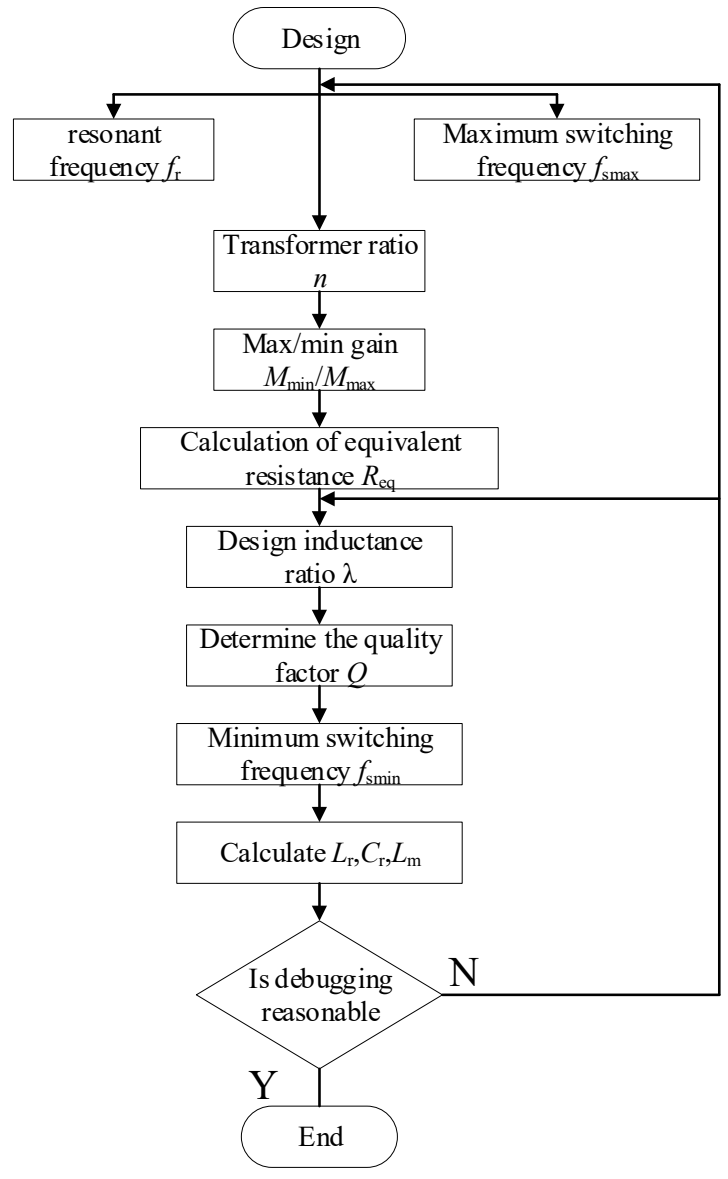

Figure 12. Basic process of resonant circuit parameter design.

The selection of transformer excitation inductance $L_{\mathrm{m}}$ depends on the excitation current. As shown in Figure 13, the larger the excitation current, the larger the device conduction loss, and the larger the transformer capacity demand. Meanwhile, the appropriate excitation inductor can transform the MMC bridge arm sub-module switch as a soft 
switch to reduce the switching loss as shown in Figure 14. Take the excitation inductance $L_{\mathrm{m}}=10 \mathrm{mH}$, the bridge arm voltage changes from positive to zero, and bridge arm current is just around 0 , which can realize zero current switches (ZCS), and reduce the loss during switch conversion.

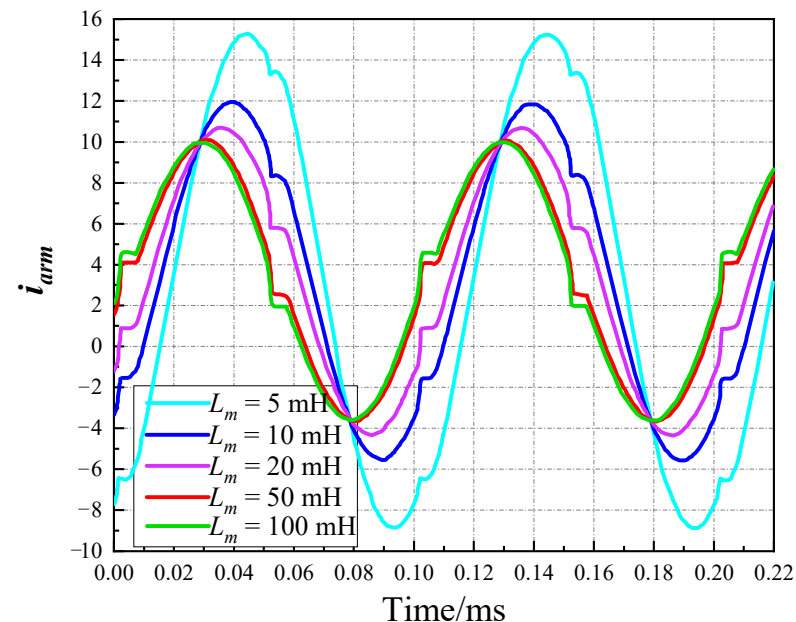

Figure 13. Effect of excitation inductance on MMC bridge arm current.

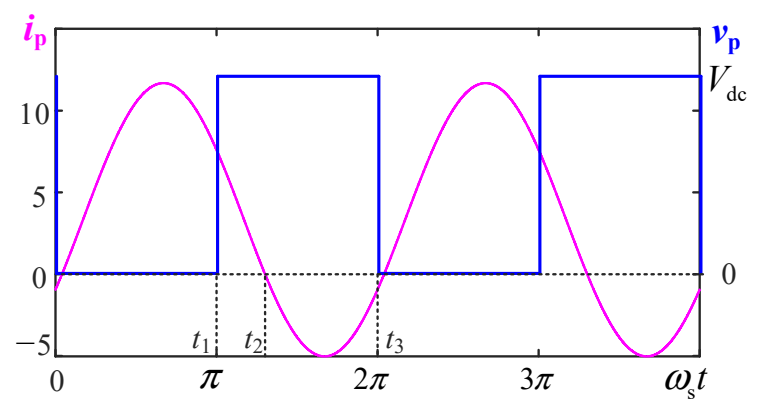

Figure 14. Phase relation diagram of bridge arm voltage and bridge arm current.

Since the resonant capacitor and resonant inductor satisfy the resonant frequency relation, when the resonant inductor is constant and the resonant capacitor is changed, the resonant voltage at both ends of the resonant capacitor will change. According to $C \mathrm{~d} U / \mathrm{d} t=i$, when the resonance current is certain, the greater $C$, the smaller the voltage at both ends of $C$ will be, as shown in Figure 15.

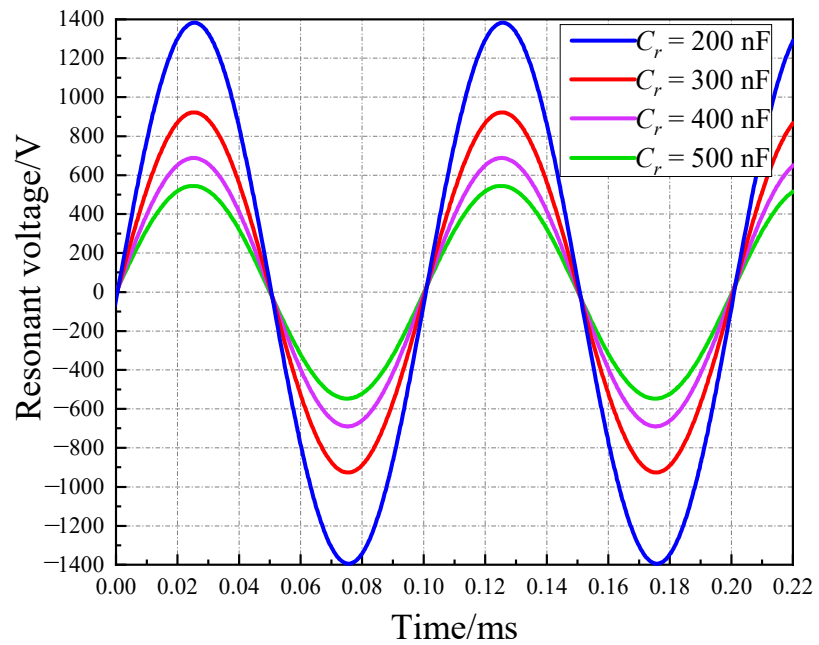

Figure 15. Effect of the resonant capacitor on the resonant voltage at both ends. 
In addition, according to the gain demand, combined with the influence of the resonant capacitor on the resonant network gain shown in Figure 16, the compromise value of $C_{\mathrm{r}}$ and $L_{\mathrm{r}}$ is selected, $C_{\mathrm{r}}=300 \mathrm{nF}, L_{\mathrm{r}}=844.3 \mu \mathrm{H}$.

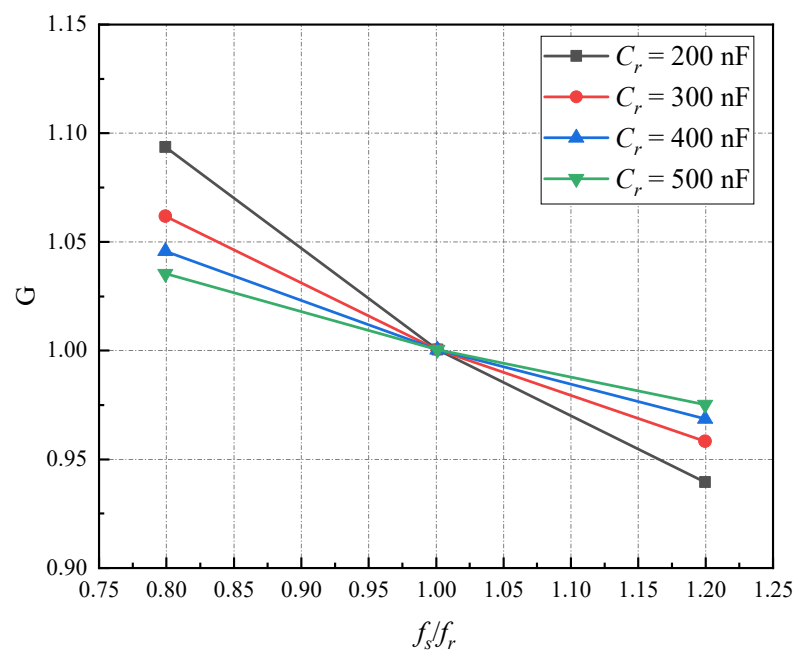

Figure 16. Influence of resonant capacitance on the gain of the resonant network.

With a high-frequency transformer with $10 \mathrm{kH}, 60 \mathrm{kVA}$ capacity, and primary and secondary side ratio of 12:1, the minimum leakage inductance $L_{\mathrm{k}}$ can be about $500 \mu \mathrm{H}$. According to Equation (5), The bridge arm inductance $L_{\mathrm{leg}}$ is $688.6 \mu \mathrm{H}$.

\subsection{Modular Unit}

The fluctuation of the capacitance-voltage of the sub-module depends on the current of the bridge arm and the switching frequency. The square wave frequency is the resonance frequency under the minimum input voltage. When the output end is a full load, the FHA method is adopted to obtain the fundamental wave equivalent circuit of the resonance network, as shown in Figure 17.

$$
v_{\mathrm{NO}, 1}=\frac{2}{\pi} V_{\mathrm{dc}} \sin \left(\omega_{\mathrm{s}} t\right)
$$

when the fundamental frequency is equal to the resonant frequency, $L_{\mathrm{r}}$ and $C_{\mathrm{r}}$ are equivalently short-circuited, and the resonant current amplitude is as follows:

$$
I_{\mathrm{r}}=\frac{V_{\mathrm{NO}, 1}}{Z_{\mathrm{NO}}}=\frac{\frac{2}{\pi} V_{\mathrm{dc}}}{\omega_{\mathrm{s}} L_{\mathrm{m}} / / R_{\mathrm{eq}}}=16.7 \mathrm{~A}
$$

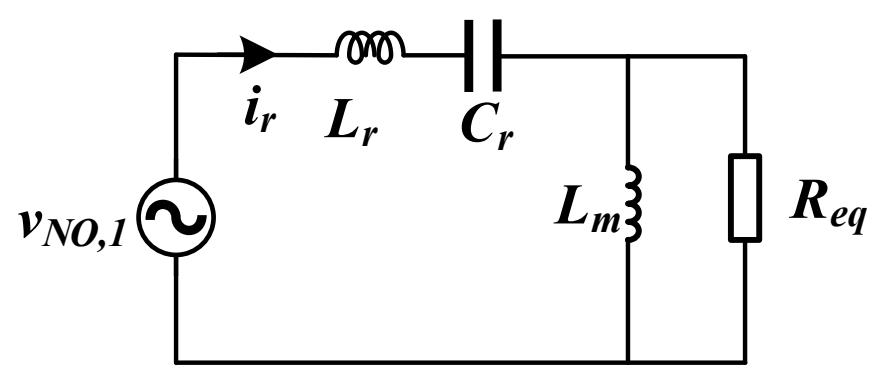

Figure 17. Equivalent circuit of LLC resonator fundamental wave.

The input voltage angle of the phase lag square wave of theresonance current is as follows:

$$
\varphi=\arctan \frac{R_{\mathrm{eq}}}{\omega_{\mathrm{s}} L_{\mathrm{m}}} \approx 30.8^{\circ}
$$


Ignoring the loss of converter, the maximum input DC is as follows:

$$
I_{\mathrm{dc}}=\frac{P_{\mathrm{o}}}{V_{\mathrm{dc}, \min }}=4.45 \mathrm{~A}
$$

The resonant current is divided equally between the upper and lower arms of MMC, and the expression of arm current is obtained as follows:

$$
i_{\mathrm{p}}=I_{\mathrm{dc}}+\frac{1}{2} I_{\mathrm{r}} \sin \left(\omega_{\mathrm{s}} t-\varphi\right)
$$

when the MMC bridge arm square wave is outputted, the charging and discharging of the sub-module capacitor occurs during the operation of the bridge arm sub-module. Therefore, combined with the voltage expression of the upper bridge arm, the waveform of the bridge arm voltage and the bridge arm current can be drawn, as shown in Figure 18.

$$
v_{\mathrm{p}}= \begin{cases}0, & n T_{\mathrm{s}}<t<n T_{\mathrm{s}}+T_{\mathrm{s}} / 2 \\ V_{\mathrm{dc}}, & n T_{\mathrm{s}}+T_{\mathrm{s}} / 2<t<(n+1) T_{\mathrm{s}}\end{cases}
$$

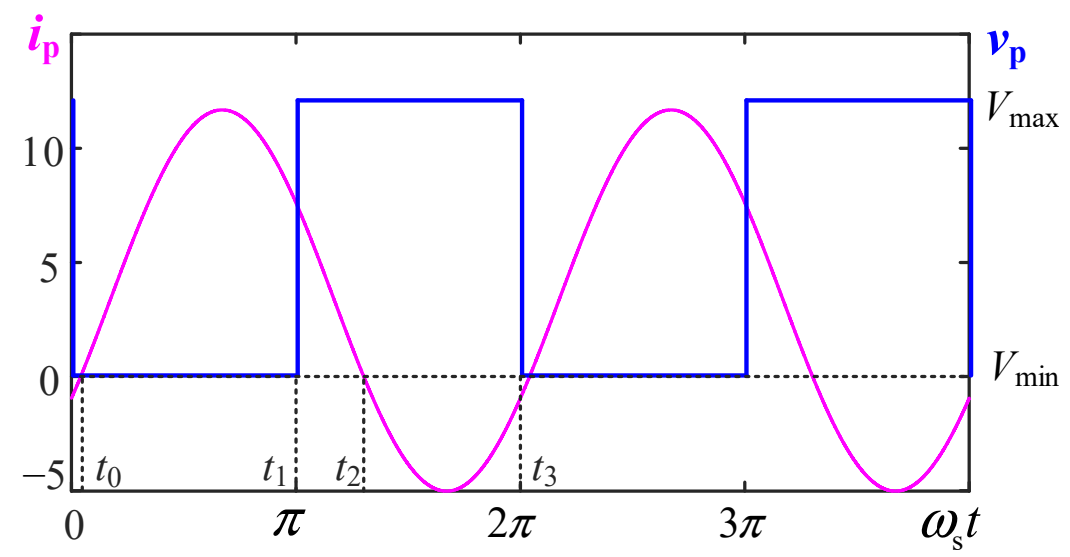

Figure 18. Phase relation diagram of bridge arm voltage and bridge arm current.

According to Figure 18, the maximum charge of the sub-module capacitor in a square wave period can be expressed as:

$$
\Delta Q=C \Delta U_{\mathrm{sm}}=\int_{t_{0}}^{t_{2}} i_{\mathrm{p}} d t
$$

where $t_{0}$ and $t_{2}$ are respectively zero-crossing time of bridge arm current. If the voltage fluctuation $\varepsilon$ of the sub-module capacitor is allowed to be $3 \%$ of the rated value, the sub-module capacitor should be selected as follows:

$$
C=\frac{\Delta Q}{\Delta U_{\mathrm{sm}}}
$$

Considering the worst operating conditions, the capacitance of the sub-module is about $10 \mathrm{uF}$ when the DC input voltage is the minimum, the switching frequency is the minimum, the excitation current is the maximum, and the load is a full load.

\subsection{Transformer}

As mentioned earlier, because of the reactive component in the resonant current, the transformer capacity is $60 \mathrm{KVA}$, which is greater than the power level of the system. Since the half-bridge MMC circuit topology is adopted in this paper, the sub-module removal voltage regulation scheme is adopted in the control voltage regulation scheme, and thus, 
the input voltage is $\pm 4.5 \mathrm{kV}$. Some devices in this circuit work in a hard switching state and thus, to reduce the switching loss, the rated working frequency of the transformer is set to $10 \mathrm{kHz}$, and the working frequency range is $8 \mathrm{kHz}-12 \mathrm{kHz}$.

The selection of core material should be solved first in the process of transformer design. The core selection of the transformer is based on the saturation flux density and core loss, both of which affect the power density and efficiency of the transformer. The magnetic core material with low loss must be selected to ensure that the temperature rise of the medium frequency transformer is in a reasonable range. Most medium frequency transformers are made of ferrite core material, which is relatively cheap. However, because of the low saturation flux density of ferrite, the power level has difficulty meeting the requirements of this project. Therefore, to reduce the volume and weight of the transformer, this design needs to use magnetic core materials with high saturation flux density and low loss, such as nanocrystalline. The disadvantages of these materials are relatively high prices and a longer processing cycle.

After the core material is determined, a preliminary evaluation of the transformer design is performed to evaluate its expected power density and loss. The process of transformer evaluation is as follows: first, the relevant parameters, including current and turn ratio should be determined according to the requirements of power and primary and secondary side voltage. Then, the cross-sectional area $A_{\mathrm{e}}$ of the transformer core is set. The simplified diagram of the core shape is shown in Figure 19. Therefore, the values of $D$ and $E$ can be determined according to the size of the window area.

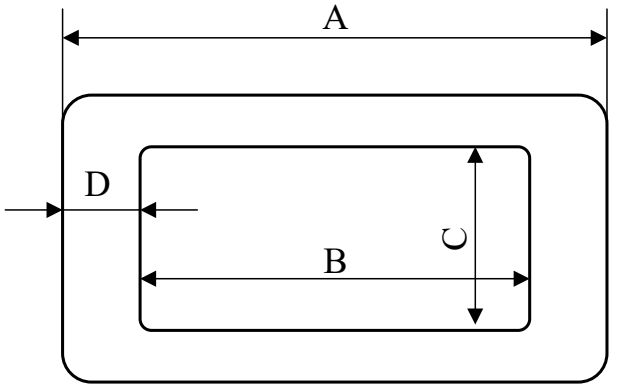

(a)

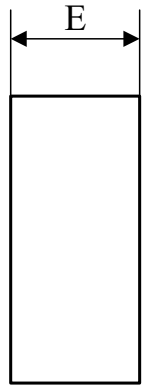

(b)

Figure 19. Magnetic core shape diagram, (a) front view of magnetic core; (b) side view of magnetic core.

The maximum working magnetic density $B_{\max }$ is determined according to the working frequency $f$ of the transformer. The winding materials of primary and secondary sides are selected based on the current density and current effective value. The adjacency effect and skin effect should be considered in this selection. In this design, the primary winding of the transformer is composed of Litz wire, and the secondary winding is composed of copper strips. Using the wire diameter $D_{\text {wire }}$ and wire area $S_{\text {wire }}$ of Litz wire, the number of turns of the primary and secondary winding is determined according to Equation (19):

$$
\begin{aligned}
& N_{\text {pri }}=\frac{V_{t}}{2 f \cdot 2 B_{\max } \cdot A_{e}} N_{s e c}=\frac{N_{\text {pri }}}{N_{\text {ratio }}} I_{r m s s}=I_{r m s p} \cdot \frac{N_{\text {pri }}}{N_{s e c}} \\
& N_{\text {wirep }}=\frac{I_{r m s p}}{J \cdot S_{\text {wire }}} N_{\text {wires }}=\frac{I_{r m s s}}{J \cdot S_{\text {wire }}}
\end{aligned}
$$

where $N_{p r i}$ is the number of Litz wire strands on the primary side, $V_{t}(\mathrm{~L})$ is the volume of transformer, $f$ is the working frequency of transformer, $N_{\text {ratio }}$ is the turn ratio of transformer, $N_{s e c}$ is the number of Litz wire strands on the secondary side, $I_{r m s p}(\mathrm{~A})$ is the effective value of primary side current, $I_{r m s s}(\mathrm{~A})$ is the effective value of secondary side current, $J\left(\mathrm{~A} / \mathrm{m}^{2}\right)$ is the maximum current density, $N_{\text {wirep }}$ and $N_{\text {wirep }}$ are the turns of the primary and secondary sides of the transformer, respectively. 
The size of the transformer core is estimated according to the utilization rate of the window:

$$
\begin{aligned}
& A_{w}=\frac{N_{\text {pri }} \cdot N_{\text {wirep }}+N_{\text {sec }} \cdot N_{\text {wires }}}{K_{u} \cdot D_{\text {wire }}} \\
& C=\sqrt{A_{w} / 2} ; B=A_{w} / C ; A=B+2 D ;
\end{aligned}
$$

where $K_{u}$ is the window utilization of transformer core, $A_{w}$ is the window area of magnetic core, $A, B, C, D$ are shown in Figure 19.

The volume and mass of the transformer are calculated according to the size and density of the magnetic core material. The core loss of the transformer is calculated using the Steinmetz formula together with the working magnetic density and working frequency of the transformer. Finally, the total loss of the transformer is calculated according to the core loss and winding copper loss to verify whether the design requirements are met. The final evaluation results are shown in Table 1.

Table 1. Transformer design results.

\begin{tabular}{cccccc}
\hline Transformer & $\begin{array}{c}\text { Maximum } \\
\text { Flux/T }\end{array}$ & Current Density & Efficiency/\% & $\begin{array}{c}\text { Size/mm } \\
\text { (Length } * \text { Width } * \text { Height) }\end{array}$ & Volume/L \\
\hline $60 \mathrm{kVA} / 10 \mathrm{kHz}$ & 0.302 & 4.04 & 99.6 & $225 * 225 * 127$ & 6.429375 \\
\hline
\end{tabular}

\section{Simulation and Laboratory Test}

\subsection{Simulation Results}

Based on the above analysis, the simulation circuit is built, and the specific simulation parameters are shown in Table 2. The parameters of each component are selected based on theoretical calculation, and the capacitance of the sub-module and output filter is selected according to the worst case. At the same time, the system can also achieve the highest potential power density.

\begin{tabular}{|c|c|c|c|}
\hline Electronic Component & Value & Electronic Component & Value \\
\hline DC input voltage $V_{d c}$ & $-9 \mathrm{kV} \sim-15 \mathrm{kV}$ & Bridge arm inductance $L_{l e g}$ & $688.6 \mu \mathrm{H}$ \\
\hline DC output voltage & $375 \mathrm{~V}$ & $\begin{array}{l}\text { Leakage inductance of } \\
\text { transformer } L_{k}\end{array}$ & $844.3 \mu \mathrm{H}$ \\
\hline Output power $P_{o}$ & $40 \mathrm{~kW}$ & Resonant capacitor $C_{r}$ & $300 \mathrm{nF}$ \\
\hline $\begin{array}{c}\text { Number of sub-modules of single } \\
\text { bridge } \operatorname{arm} N\end{array}$ & $15+3$ & $\begin{array}{l}\text { Excitation inductance of } \\
\text { transformer } L_{m}\end{array}$ & $10 \mathrm{mH}$ \\
\hline Capacitance of sub-module $C_{S m}$ & $10 \mathrm{uF}$ & $\begin{array}{l}\text { Closed-loop frequency } \\
\text { modulation range } f_{s}\end{array}$ & $8 \mathrm{kHz} \sim 12 \mathrm{kHz}$ \\
\hline $\begin{array}{l}\text { Rated voltage of sub-module } V_{s m} \\
\text { resonant frequency } f_{r}\end{array}$ & $\begin{array}{l}655 \mathrm{~V} \\
10 \mathrm{k} \mathrm{Hz}\end{array}$ & $\begin{array}{c}\text { DC input capacitance } C_{\text {in }} \\
\text { DC output filter capacitor } C_{o}\end{array}$ & $\begin{array}{l}10 \mu \mathrm{F} \\
600 \mu \mathrm{F}\end{array}$ \\
\hline
\end{tabular}

Table 2. Simulation model parameters.

The simulation first verifies the requirements of the circuit in the steady-state conditions, and the output voltage waveform is shown in Figure 20. Under different input voltages, a certain error in the output voltage can be found only through the MMC sub-module removal voltage regulation. When the output voltage closed-loop feedback frequency modulation control is adopted, the output voltage is stable at $375 \mathrm{~V}$ (as shown in the figure, the curve in the red dotted box), and the ripple is less than $1.5 \mathrm{~V}(0.5 \%)$. 


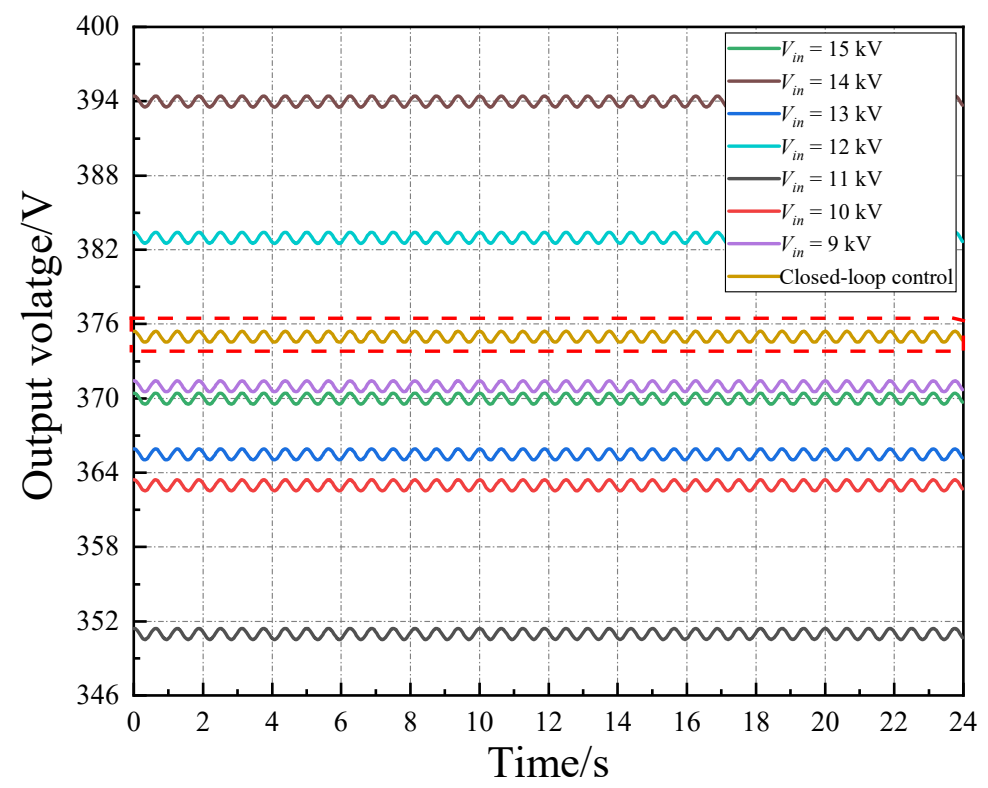

Figure 20. Output voltage steady-state waveform.

Figure 21 shows that under the rated input voltage, when switching from half-load to full load, the transition process is about $5 \mathrm{~ms}$ and the voltage fluctuation is $5 \mathrm{~V}(1.33 \%)$. The high voltage DC converter shows good dynamic stability.

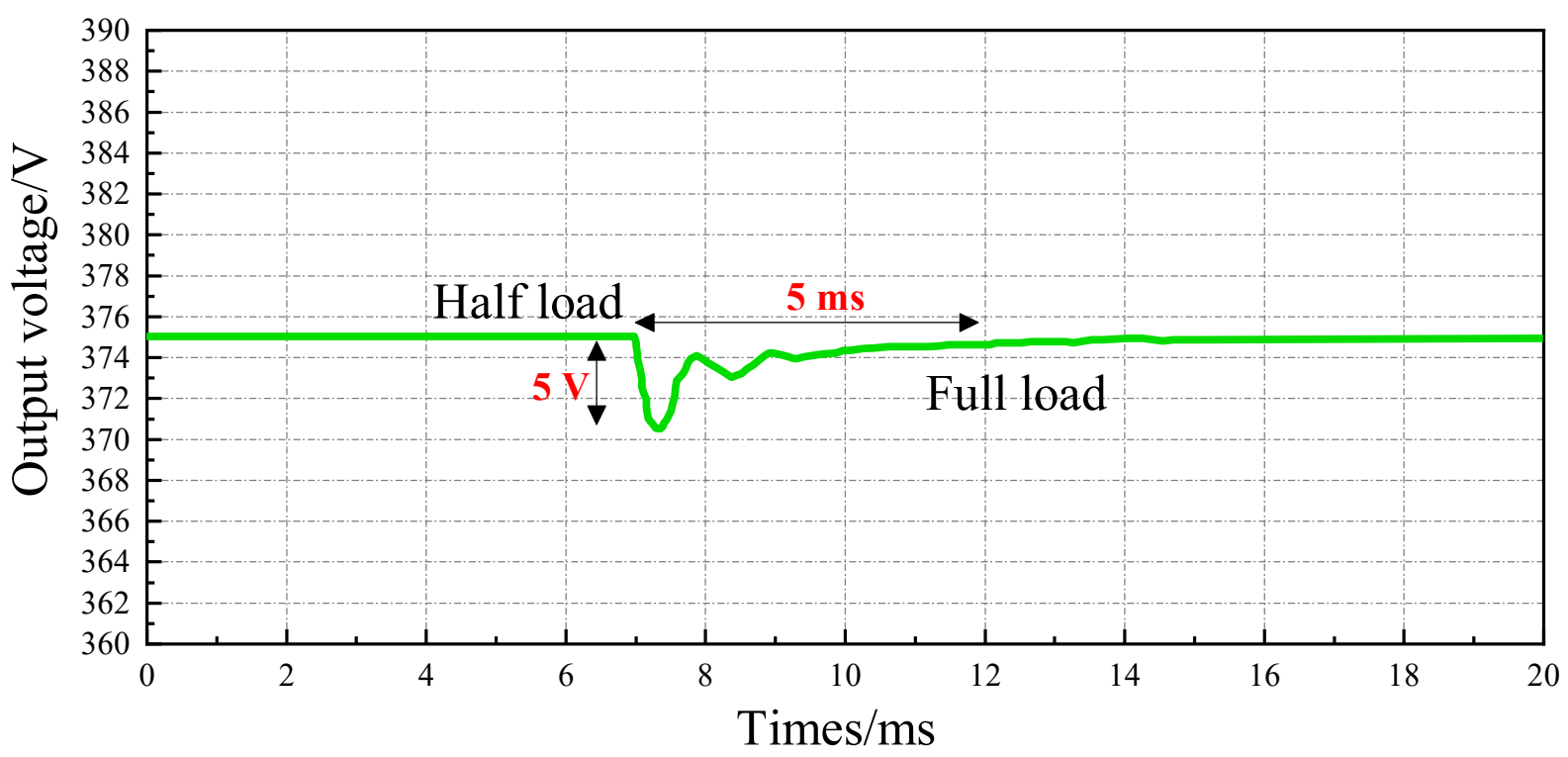

Figure 21. Output voltage waveform of half-load switching to full load.

Figure 22 is the output voltage waveform of the load continuous change experiment. When the load increases, the current required by the load suddenly increases, and because the inductance element impedes the current mutation, the output capacitor discharges to provide the current required by the load, so there is a drop in the output voltage. When the load decreases, the change in the output voltage is just the opposite. Figure 22 shows that the fluctuation of output voltage from full load to no-load output voltage is less than $10 \mathrm{~V}$ $(2.7 \%)$, and all indicators meet the design requirements. 


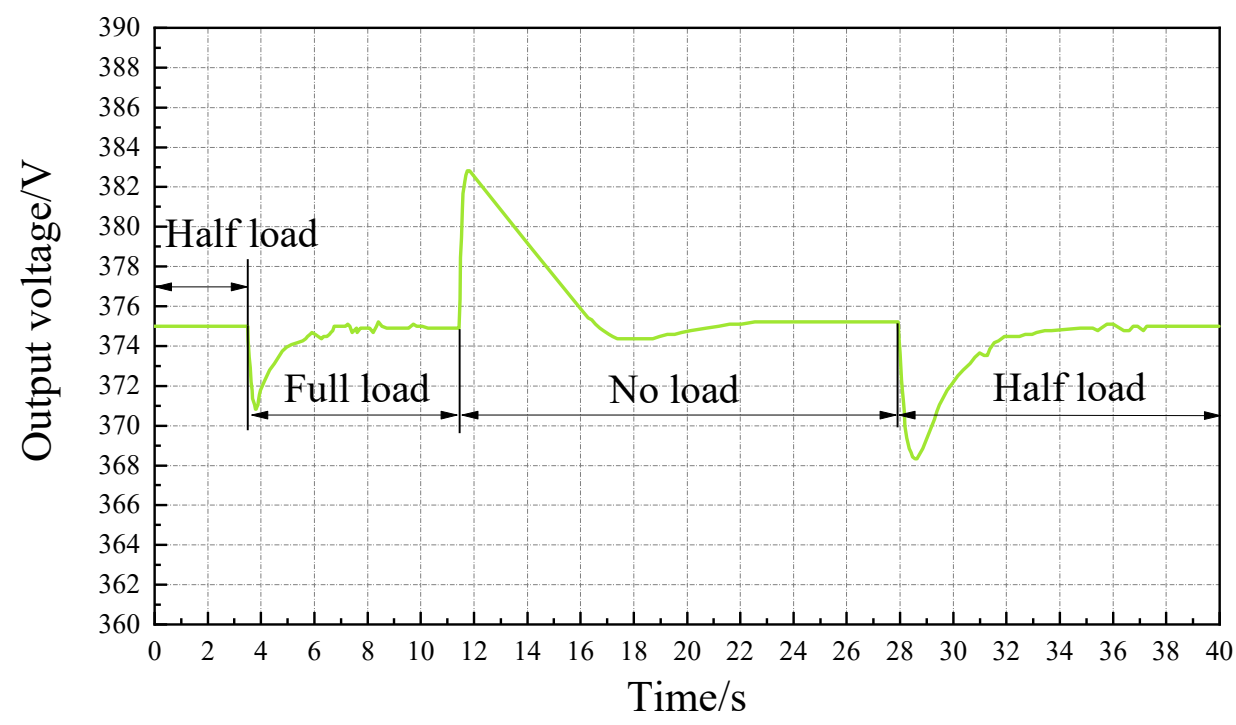

Figure 22. Waveform of output voltage during half-load, full load, and no-load switching.

Figure 23 shows the waveform of the sub-module capacitor voltage and output DC voltage during startup. The capacitor voltage of the sub-module can be charged steadily to the rated voltage, and the output DC voltage also rises steadily to the rated output voltage of $375 \mathrm{~V}$. No obvious overshoot phenomenon was observed. The above simulation results show the circuit can start under light load.

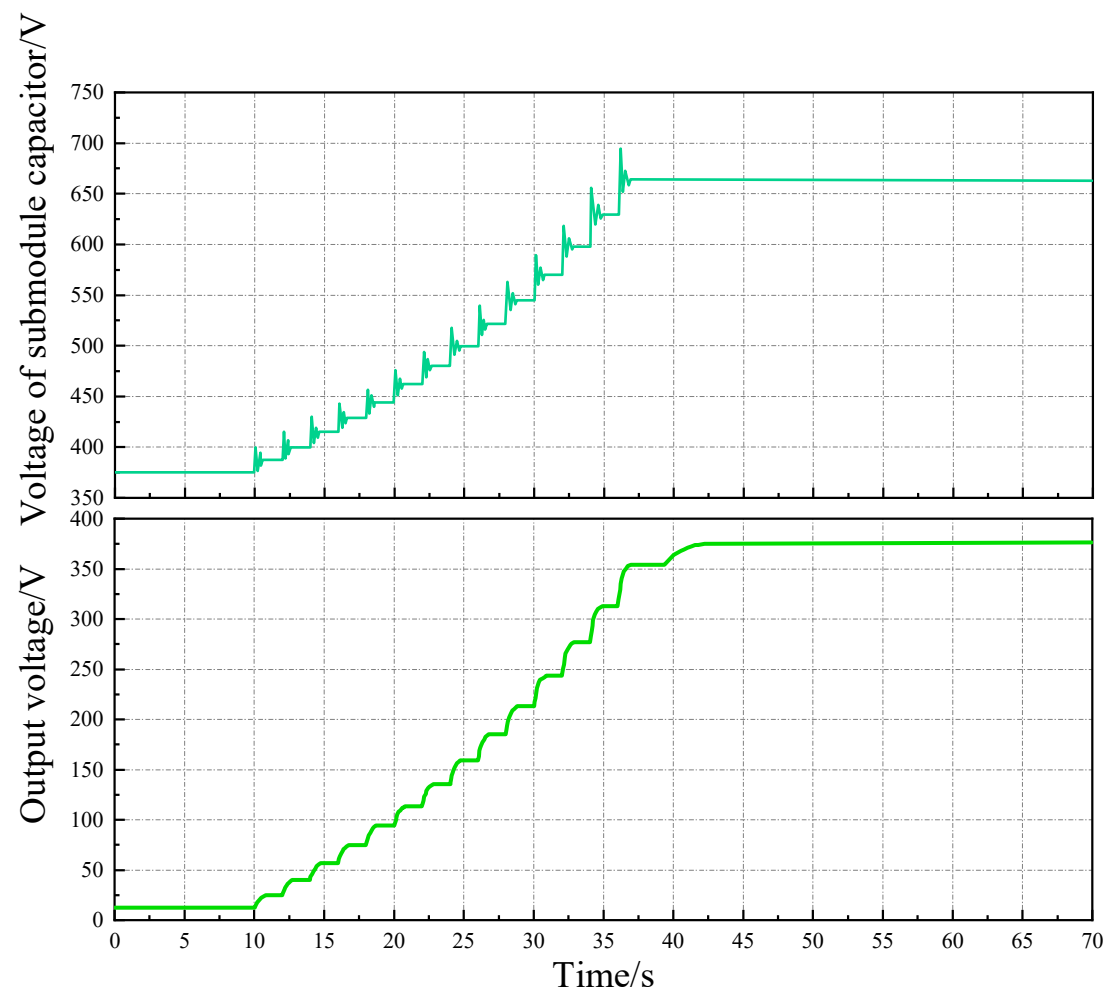

Figure 23. Waveform of sub-module capacitor voltage and output DC voltage during light load startup. 


\subsection{Experimental Results}

To verify the above simulation results, the experimental platform of HVC electric energy characteristics was built in the laboratory as shown in Figure 24. The platform includes DC power supply, HVC, and electronic load. In this section, the load change and soft start experiment of HVC are carried out in the laboratory experiment.

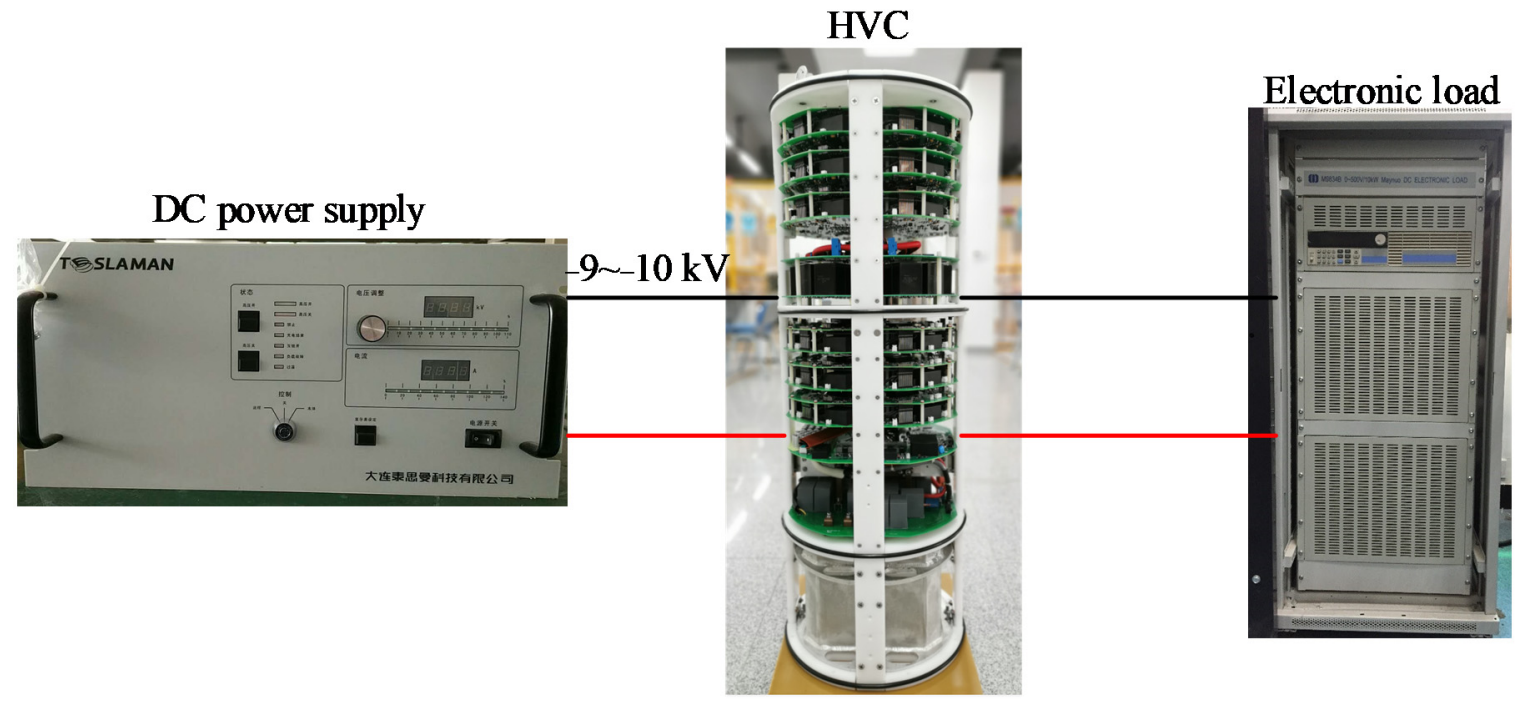

Figure 24. Experimental platform of HVC electric energy characteristics.

First, the load change experiment is carried out. The output load of HVC is switched between no-load, full load, and half-load, and the load change characteristic waveform of HVC is obtained as shown in Figure 25. It can be concluded that under the rated input voltage, the output voltage fluctuation from full load to no-load or from no-load to full load is less than $10 \mathrm{~V}$, and the output voltage fluctuation from half-load to full load is less than $5 \mathrm{~V}$, which is consistent with the simulation results. Moreover, the output voltage can return to a stable state within a very short time after load change, indicating that the proposed HVC has strong anti-load disturbance characteristics.

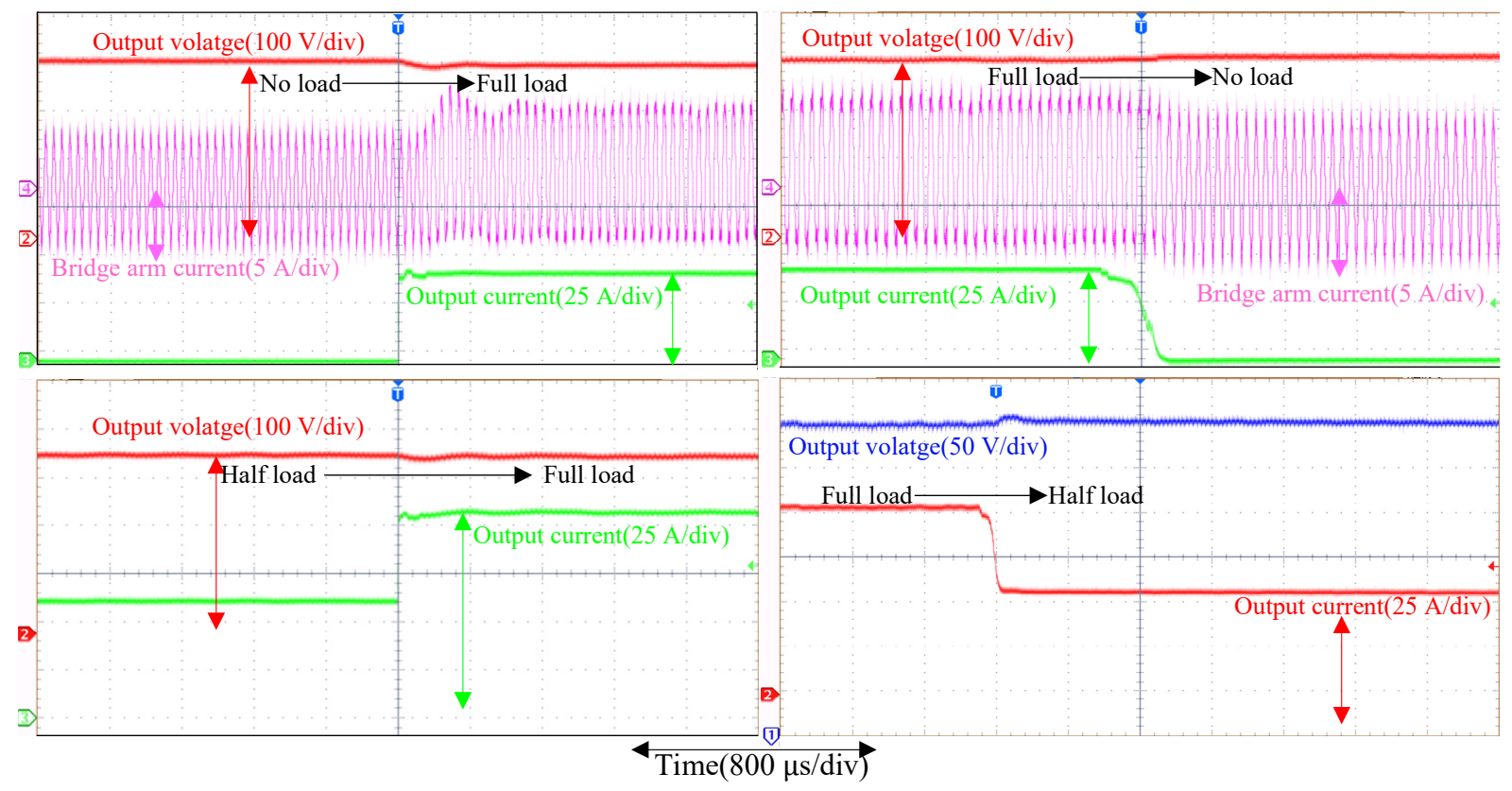

Figure 25. Load change experimental result. 
The soft-start experiment of HVC is carried out to verify the soft-start function of HVC. Start HVC under light load to get output voltage and bridge arm current waveform of HVC. As shown in Figure 26, the output voltage is increased steadily to the rated output voltage of $375 \mathrm{~V}$ without overshoot after the HVC is started. The bridge arm current also gradually increases to the maximum value and then stabilizes, avoiding the impact on the components. It is consistent with the simulation results shown in Figure 23, which meet the design requirements, and verifies that HVC can realize the soft-start function.

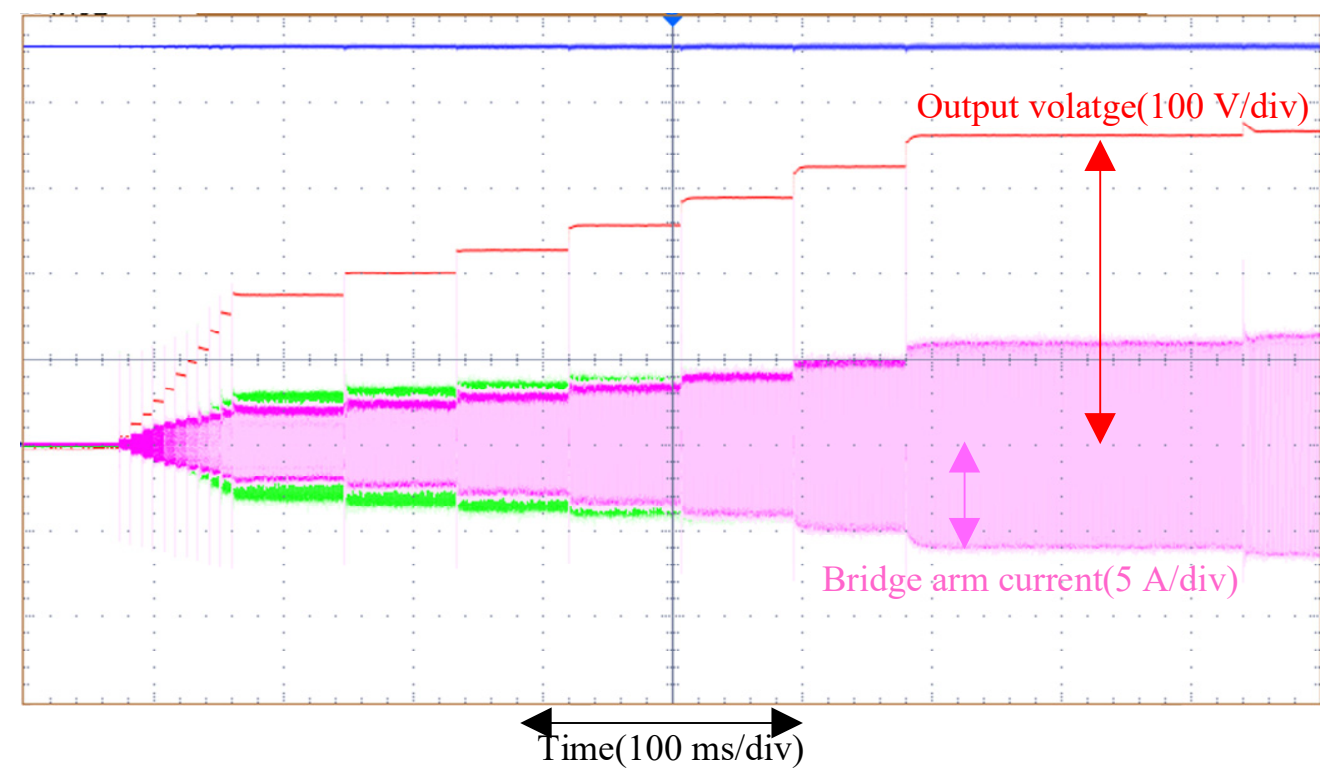

Figure 26. Experimental result of soft start.

\section{Conclusions}

Based on the defects of the traditional multi-module series-parallel electric energy converter, this paper presents an HVC based on MMC-LLC topology. The main circuit of HVC is designed in detail, including system topology, module circuit, resonant circuit, and control scheme. Through the combination of sub-module removal voltage regulation and closed-loop control, the converter can still output a stable voltage of $375 \mathrm{~V}$ when the input voltage changes. By selecting whether the capacitance of $\mathrm{K}$ sub-module in $\mathrm{MMC}$ upper and lower bridge arm remains put into circuit, the voltage range of MMC bridge arm is changed, and the voltage regulation can be realized. The topological parameters of the main circuit are discussed and optimized by simulation. The resonant circuit and sub-module circuit are simulated, and a complete set of design method is given. The appropriate inductance and capacitance parameters are selected for subsequent prototype production and experimental verification. At the same time, the parameters of the transformer are designed, the requirements of the transformer are analyzed, and the parameters of the transformer are determined according to the working conditions of the transformer. The modular sub-module and centralized transformer structure enables the converter to easily isolate high voltage and has the characteristics of small volume and high-power density. Finally, the simulation and laboratory experiments of converter soft start and load change are carried out. The simulation and experiment results show the proposed HVC meets the design requirements and has a good application prospect. It can be applied to the submarine power transmission and distribution needs with its wide range, large transformation ratio, and high efficiency. 
Author Contributions: Conceptualization, F.Z.; formal analysis, F.Z. and Z.Z.; supervision, Z.Z.; data curation, S.X. and J.N.; validation, S.X. and K.X. and H.G.; writing-original draft, S.X.; writing-review and editing, S.X.; project administration, K.X.; software, J.N., H.G., and Y.N.; funding acquisition, Y.W.; investigation, Y.W.; methodology, Q.X.; resources, Q.X. All authors have read and agreed to the published version of the manuscript.

Funding: This work is supported by the National Natural Science Foundation of China (No.41676089), the Natural Science Foundation of Zhejiang Province of China (No. LY18E090003), and the Fundamental Research Funds for the Central Universities (No. 2018QNA4005).

Institutional Review Board Statement: Not applicable.

Informed Consent Statement: Not applicable.

Data Availability Statement: Not applicable.

Conflicts of Interest: The authors declare no conflict of interest. The funders had no role in the design of the study; in the collection, analyses, or interpretation of data; in the writing of the manuscript, or in the decision to publish the results.

\section{References}

1. Yu, Y.; Xu, H.; Xu, C. A Sensor Web Prototype for Cabled Seafloor Observatories in the East China Sea. J. Mar. Sci. Eng. 2019, 7, 414. [CrossRef]

2. Yu, J.; Zhang, S.; Yang, W.; Xin, Y.; Gao, H. Design and Application of Buoy Single Point Mooring System with Electro-OpticalMechanical (EOM) Cable. J. Mar. Sci. Eng. 2020, 8, 672. [CrossRef]

3. Xiao, S.; Yao, J.; Chen, Y.; Li, D.; Zhang, F.; Wu, Y. Fault Detection and Isolation Methods in Subsea Observation Networks. Sensors 2020, 20, 5273. [CrossRef] [PubMed]

4. Yu, Y.; Xu, H.; Xu, C. An Object Model for Seafloor Observatory Sensor Control in the East China Sea. J. Mar. Sci. Eng. 2020, 8, 716. [CrossRef]

5. Von Alt, C.J.; Grassle, J.F. Leo-15 an Unmanned Long Term Environmental Observatory. In Proceedings of the OCEANS'92. Mastering the Oceans through Technology, Newport, RI, USA, 26-29 October 1992; pp. 849-854.

6. Kawaguchi, K.; Momma, H.; Iwase, R. VENUS project-Submarine cable recovery system. In Proceedings of the 1998 International Symposium on Underwater Technology, Tokyo, Japan, 17 April 1998; pp. 448-452.

7. Butler, R.; Chave, A.D.; Duennebier, F.K.; Yoerger, D.R.; Petitt, R.; Harris, D.; Wooding, F.B.; Bowen, A.D.; Bailey, J.; Jolly, J.; et al. Hawaii-2 observatory pioneers opportunities for remote instrumentation in ocean studies. Eos Trans. Am. Geophys. Union 2000, 81, 157-163. [CrossRef]

8. Kasahara, J.; Shirasaki, Y.; Momma, H. Multidisciplinary geophysical measurements on the ocean floor using decommissioned submarine cables: VENUS project. IEEE J. Ocean. Eng. 2000, 25, 111-120. [CrossRef]

9. Austin, T.; Edson, J.; McGillis, W.; von Alt, C.; Purcell, M.; Petitt, R.; McElroy, M.; Ware, J.; Stokey, R. The Martha's Vineyard Coastal Observatory: A long term facility for monitoring air-sea processes. In Proceedings of the OCEANS 2000 MTS/IEEE Conference and Exhibition, Providence, RI, USA, 11-14 September 2000; pp. 1937-1941.

10. Duennebier, F.K.; Harris, D.W.; Jolly, J.; Caplan-Auerbach, J.; Jordan, R.; Copson, D.; Stiffel, K.; Babinec, J.; Bosel, J. HUGO: The Hawaii Undersea Geo-Observatory. IEEE J. Ocean. Eng. 2002, 27, 218-227. [CrossRef]

11. Henthorn, R.G.; Hobson, B.W.; McGill, P.R.; Sherman, A.D.; Smith, K.L. MARS Benthic Rover: In-situ rapid proto-testing on the Monterey Accelerated Research System. In Proceedings of the OCEANS 2010 MTS/IEEE SEATTLE, Seattle, WA, USA, 20-23 September 2010; pp. 1-7.

12. Dewey, R.; Tunnicliffe, V. VENUS: Future science on a coastal mid-depth observatory. Scientific Use of Submarine Cables and Related Technologies. In Proceedings of the 2003 International Conference Physics and Control, Tokyo, Japan, 25-27 June 2003; pp. 232-233.

13. Woodroffe, A.M.; Pridie, S.W.; Druce, G. The NEPTUNE Canada Junction Box: Interfacing science instruments to sub-sea cabled observatories. In Proceedings of the OCEANS 2008-MTS/IEEE Kobe Techno-Ocean, Kobe, Japan, 8-11 April 2008; pp. 1-5.

14. Yinger, P.; Tennant, P.; Reardon, J.; Harkins, G.; McGuire, C.; Harrington, M.; Mulvihill, M. Commissioning of a system that terminates on the seafloo. In Proceedings of the 2013 OCEANS-San Diego, San Diego, CA, USA, 23-27 September 2013; pp. 1-6.

15. Delory, E.; Waldmann, C. ESONET, the European Seas Observatory Network. In Proceedings of the World Summit on Ocean Innovations, Kobe, Japan, 8-11 April 2008.

16. Kawaguchi, K.; Kaneda, Y.; Araki, E. The DONET: A real-time seafloor research infrastructure for the precise earthquake and tsunami monitoring. In Proceedings of the OCEANS 2008-MTS/IEEE Kobe Techno-Ocean, Kobe, Japan, 8-11 April 2008; pp. 121-124.

17. Kanazawa, T. Japan Trench earthquake and tsunami monitoring network of cable-linked 150 ocean bottom observatories and its impact to earth disaster science. In Proceedings of the 2013 IEEE International Underwater Technology Symposium (UT), Tokyo, Japan, 5-8 March 2013; pp. 1-5. 
18. Chen, Y.H.; Yang, C.J.; Li, D.J.; Jin, B.; Chen, Y. Study on 10 kVDC powered junction box for a cabled ocean observatory system. China Ocean Eng. 2013, 27, 265-275. [CrossRef]

19. Chen, Y.; Xiao, S.; Li, D. Stability Analysis Model for Multi-Node Undersea Observation Networks. Simul. Model. Pract. Theory 2019, 97, 101971. [CrossRef]

20. Yang, F.; Lyu, F. A Novel Fault Location Approach for Scientific Cabled Seafloor Observatories. J. Mar. Sci. Eng. 2020, 8, 190. [CrossRef]

21. Dekka, A.; Wu, B.; Fuentes, R.L.; Perez, M.; Zargari, N.R. Evolution of Topologies, Modeling, Control Schemes, and Applications of Modular Multilevel Converters. IEEE J. Emerg. Sel. Top. Power Electron. 2017, 5, 1631-1656. [CrossRef]

22. Kenzelmann, S.; Rufer, A.; Dujic, D.; Canales, F.; De Novaes, Y.R. Isolated DC/DC Structure Based on Modular Multilevel Converter. IEEE Trans. Power Electron. 2015, 30, 89-98. [CrossRef]

23. Zhang, J.; Wang, Z.; Shao, S.A. Three-Phase Modular Multilevel DC-DC Converter for Power Electronic Transformer Applications. IEEE J. Emerg. Sel. Top. Power Electron. 2017, 5, 140-150. [CrossRef] 